
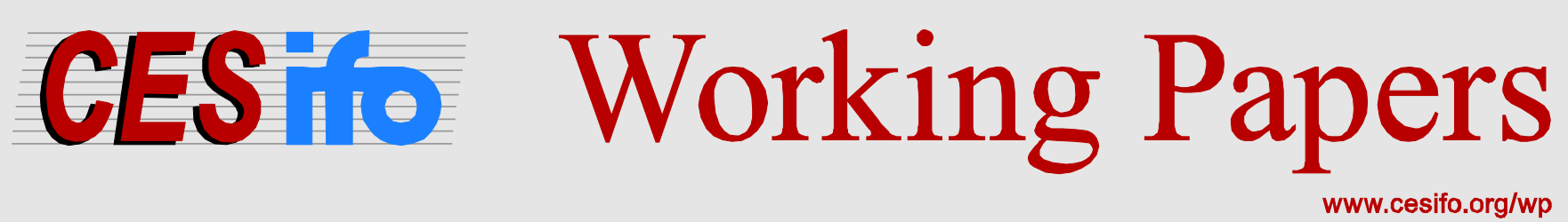

\title{
Dynasties and the Political Budget Cycle
}

\author{
Gianmarco Daniele \\ Paul Vertier
}

CESIFO WORKING PAPER NO. 6231

CATEgory 2: Public CHOICE

DECEMBER 2016

An electronic version of the paper may be downloaded

- from the SSRN website: Www.SSRN.com

- from the RePEc website: Www.RePEc.org

- from the CESifo website: www.CESifo-group.org/wp 


\title{
Dynasties and the Political Budget Cycle
}

\begin{abstract}
Families often play a significant role in representative democracies. In this paper, we test the extent to which dynastic and non-dynastic leaders differ in their policy making. Our empirical analysis focuses on local politics in Italy, using a large sample of mayors and mayoral candidates in the period 1985-2012. We highlight that dynastic candidates have more successful political careers and that power is self-perpetuating, as those in power are more likely to establish a dynasty. We then test whether dynastic mayors enforce different policies than their non-dynastic counterparts. We find no effect on average spending, revenues or transfers. Conversely, we show that dynastic mayors increase spending and obtain higher transfers during the year prior to an election, especially when they are eligible to run for re-election. We discuss mechanisms that might explain this strategic behavior.
\end{abstract}

JEL-Codes: H110.

Keywords: dynasties, political budget cycles.

\author{
Gianmarco Daniele \\ Institut d'Economia Barcelona (IEB) \\ Facultat d'Economia i Empresa \\ University of Barcelona \\ c/ John M. Keynes, 1-11 \\ Spain - 08034 Barcelona \\ daniele.gianmarco@gmail.com
}

\author{
Paul Vertier \\ Department of Economics \\ Sciences Po Paris \\ 28 rue des Saints-Pères \\ France - 75007 Paris \\ paul.vertier@sciencespo.fr
}

This version: November 28, 2016

We thank Toke Aidt, Pamela Campa, Bruno Caprettini, Guillaume Chapelle, Ernesto Dal Bó, Gemma Dipoppa, Jean-Benoît Eyméoud, Jon Fiva, Benny Geys, Sergei Guriev, Emeric Henry, Roland Hodler, Elise Huillery, Giovanni Mastrobuoni, Luigi Pascali, Amedeo Piolatto, Maria Camila Porras, Pablo Querubin, Shanker Satyanath, David Seim, Eve Sihra, Albert Solé-Ollé, Denni Tommasi, Ragnar Torvik, Michael Visser and Simon Weber for useful comments on earlier versions of this paper. We also thank seminar participants at Institut d'Economia Barcelona (IEB), Sciences Po, University of Oslo, the 10th CESifo Workshop on Political Economy in Dresden, and the "Culture, Institutions and Development” Workshop in Galatina. 


\section{Introduction}

Even though political positions in democratic societies are generally awarded via elections, families often continue to play a significant role in politics. In fact, political dynasties are common in diverse settings including Argentina (Rossi (2016)), Japan (Fukai and Fukui (1992); Asako et al. (2015)), the Philippines (Querubin (2013)) and the United States (Dal Bó et al. (2009); Feinstein (2010)). The emerging academic literature on political dynasties has so far predominantly focused on whether and how political dynasties arise and/or persist, and has not investigated their effects. By contrast, this paper focuses on whether dynastic elected leaders behave differently from other politicians once they are in office.

Two main hypotheses suggest that this might be the case. First, previous studies show that dynastic politicians are electorally more successful (Dal Bó et al. (2009); Rossi (2016); Querubin (2013)). In turn, dynastic leaders might also be more capable of enforcing their preferred policy agenda due to inherited political skills, for example the ability to mobilize local networks, negotiate with local elites and exploit their family's reputation (Rossi (2016); Querubin (2013); Dal Bó et al. (2009); Feinstein (2010)). However, such reasoning also suggests that dynastic leaders might behave less strategically when setting their agenda, since they benefit from an electoral advantage that makes it less important for them to signal their competence. ${ }^{1}$

A second hypothesis is that dynastic politicians might receive greater gains from politics, due to their inherited political skills. In turn, they will implement policies that enable them to remain in office. ${ }^{2}$ Overall, dynastic politicians might behave differently from non-dynastic politicians once in office both because they can (thanks to inherited political skills) and because they want to (due to higher returns from politics).

\footnotetext{
${ }^{1}$ This is in line with Besley and Reynal-Querol (2015), who argue that dynastic leaders perform particularly well when constraints on the executive are weak, and dynastic transmission of power is easier.

${ }^{2}$ For instance, dynastic members might take advantage of their predecessor's networks. Indeed, political networks have been shown to increase politicians' revenues, the revenues of their relatives (Folke et al. (2016), Labonne and Fafchamps (2015), Fisman et al. (2012), Querubin and Snyder Jr (2011), Eggers and Hainmueller (2009)) and the profits of connected firms (Faccio (2006),Amore and Bennedsen (2013) Gagliarducci and Manacorda (2014)). Moreover, dynastic politicians might prefer a political career for reputational reasons, i.e., they might perceive a higher utility (than non-dynastic politicians would) from holding political office (this motivation is related to the political science literature on public service motivations (e.g., Houston (2000)). Finally, an alternative explanation is that dynastic politicians might suffer from a "Carnegie effect" (Durante et al. (2011)) if the advantage granted by their elected ancestors led them to underinvest in their own human capital: in this case, a worse outside option might incentivize dynastic politicians to shape policies that maximize their chances of re-election.
} 
In this paper, we test these two hypotheses using data on Italian local politicians from the period 1985-2012. We first show that dynastic politicians have different careers and different electoral performances: they are more likely to win local elections and get elected in higher levels of government (i.e. regional parliaments) than non-dynastic politicians. Indeed, political power is persistent in Italian municipalities: an elected mayor is twice as likely to have a relative in office as a non-elected mayoral candidate. These striking differences are in line with the relevance of inherited political skills, and motivate our interest in the policy-making side. Our main finding is that dynastic mayors are more likely to increase public spending in the year before an election. They increase spending, especially capital expenditure, and finance such spending mostly through higher transfers. The increase is substantial - between 70 and 200 euros per capita depending on the preferred specification.

In line with our hypotheses, we find that dynastic politicians appear to be more powerful and more strategic. First, they react to electoral incentives, as we find evidence of a political budget cycle (PBC) only for dynastic mayors at the end of their first term, i.e., those who are eligible to run for re-election (Italian mayors have a two-term limit). Moreover, we show that dynastic mayors are more likely to have higher pre-electoral spending in more contested elections. Second, consistent with the theorized links between dynastic politicians and inherited political skills and higher gains from politics, we find that: i) dynastic politicians enter into politics at a younger age; ii)among dynastic mayors, PBCs are stronger for the youngest and less experienced, who are likely to be more concerned about managing their careers; iii) while dynastic mayors employed in liberal professions - which are based on local networks -have substantially stronger PBCs, we do not find that they enforce higher PBCs in Southern Italy, which is characterized by a higher level of clientelism and lower social capital; iv) this effect is unlikely to be channeled by a worse outside option: even though dynastic mayors are likely to be less educated, more-educated dynastic mayors are not less likely to run PBCs. ${ }^{3}$

As our analysis covers all Italian local elected politicians in the period 1985-2012 ( $\mathrm{N}=571,824)$, we have to rely on a systematic method to identify family ties among them. In line with previous studies on academic and political dynasties (Allesina (2011); Durante et al. (2011); Querubin

\footnotetext{
${ }^{3}$ Interestingly, it appears that the electoral advantage enjoyed by dynastic mayors does not prevent them from behaving more strategically, in terms of higher spending before elections. This might be due to the relatively low cost of enforcing PBCs compared to the high cost of losing elections under electoral uncertainty.
} 
(2013)) as well as inter-generational social mobility (Clark (2014); Clark and Cummins (2015)), we define family ties as politicians who share the same surname. Clearly, this method of identification reduces the precision of our estimates. We show that our results are confirmed or reinforced when we exclude politicians with common surnames, since identifying family ties is more likely to be problematic in these cases. Our empirical strategy is robust to three different approaches: i) a panel fixed-effects estimation; ii) a regression discontinuity design (RDD) on local elections won by a close margin and iii) a matching estimation on close elections.

Our research contributes to four strands of literature. First, it enhances understanding of the strategic behaviors that elites might engage in to sustain their power in modern democracies (Michels (1915); Mosca (1939); Pareto (1901); Robinson and Acemoglu (2008)). According to theories of power transmission, dynasties, like other elite groups, strive to guarantee their power and its perpetuation to future generations (Michels (1915); Mosca (1939); Pareto (1901)). For instance, Robinson and Acemoglu (2008) provide a model of endogenous political persistence in which "the elite, by virtue of their smaller numbers and their greater expected returns from controlling politics, have a comparative advantage in investing in de facto power" (Robinson and Acemoglu (2008)).

Second, we provide additional evidence of the relevance of dynasties in the political arena in the context of an affluent European country. ${ }^{4}$ Our results are in line with previous studies showing that dynasties self-perpetuate and have an electoral advantage over non-dynastic politicians. Specifically, a first group of studies focuses on the causal impact of the length of a politician's tenure on the probability that they will have a family member in politics in the future (Dal Bó et al. (2009); Rossi (2016); Querubin (2013)). Rossi (2016), for instance, exploits an exogenous change in the Argentinian electoral law to show that a longer tenure in the Argentinian Congress increases the probability of having a relative in future congresses. Dal Bó et al. (2009) and Querubin (2013) find very similar results for the United States and the Philippines using an RDD. A second group of studies more directly investigates the electoral performance of dynastic versus non-dynastic politicians (Feinstein (2010); Asako et al. (2015), Van Coppenolle (2014)). Controlling for other individual characteristics, these studies find that dynastic politicians have a higher

\footnotetext{
${ }^{4}$ see Folke et al. (2016) and Fiva and Smith (2016) for different results in other affluent European countries.
} 
probability of success than non-dynastic politicians in national elections in the United States and Japan.

Third, we contribute to the literature on the effects of "strong" family ties, which have been linked to detrimental outcomes in terms of firms' performance (Bertrand and Schoar (2006); Bennedsen et al. (2007)), labor market participation (Alesina and Giuliano (2010)) and academic recruitment (Durante et al. (2011)). Finally, we also contribute to the literature on PBCs (Rogoff (1990); Blais and Nadeau (1992)), showing that the incentives to manipulate expenditure can vary across political groups (Persson et al. (2003)). In particular, PBCs have been linked to rent seeking: for instance, Shi and Svensson (2006) show that the size of the PBC depends on politicians' rents of remaining in power. In this light, the results of this paper complement those of Bragança et al. (2015) and Geys (2016) related to the potential rent-seeking behaviors of dynastic politicians.

The remainder of the paper is structured as follows. In Section 2, we present the institutional background and the data we use. In Section 3 we assess the importance of dynastic mayors in the political arena and describe their main characteristics. We estimate the impact of dynasties on municipal budgets in Section 4, before discussing the potential channels driving our results in Section 5, and performing robustness tests in Section 6. Section 7 concludes.

\section{Institutional background and data}

\subsection{Local politics in Italy}

The Italian political system has three levels of governance: municipalities (about 8,000 across the country) represent the lowest level, followed by regions (20) and the national level. Until 2014, provinces (110) represented another level of government between cities and regions. Nonetheless, as in most other European countries, municipal governments have important responsibilities with respect to education, social welfare, culture and recreation, city planning, transport, economic development, waste management and local police. They also have important fiscal powers, and setting the local property tax rate is the central annual financial decision (Bordignon et al. (2003)). As the share of national transfers has gradually decreased over time, 
local revenues have increasingly financed the municipal budget. However, their spending capacity is constrained by the "Internal Stability and Growth Pact," which limits the ability of municipalities to incur debts. Moreover, according to the Italian Constitution, such debts can only cover capital expenditures.

Local elections are held every five years (every four years before 2000) to elect council members and the (directly elected) mayor. The electoral system depends on the size of the municipality. In cities of fewer than 15,000 inhabitants, voters effectively have only one vote, which they cast for a candidate mayor and her list of supported candidates for the municipal council (though additional 'preference votes' for candidates within this list of candidates are possible). Elections are held in a single round, in which the mayoral candidate who obtains the most votes is selected, and her list of candidates is allocated at least $66 \%$ of the council seats. The remaining seats are allocated proportionally to the vote share of the other mayoral candidates and their lists. In municipalities with more than 15,000 inhabitants, voters choose between parties (or coalitions) that present a list of candidates for the municipal council and support a candidate mayor. Voters cast one vote for a candidate mayor and one vote for a list of candidates for the council (which can, but need not be, the list supporting a voter's preferred mayoral candidate). Elections for mayor in these larger municipalities follow a run-off system, whereby the two top candidates run in a second round if no candidate obtains an outright majority in round one. The list(s) supporting the winning mayor are allocated at least $60 \%$ of the council seats, and there is a $3 \%$ threshold for the proportional allocation of the remaining seats (see Bordignon et al. (2013) for more details). ${ }^{5}$

\subsection{Identifying political dynasties in Italy}

In this paper, we gather a wide set of data concerning local Italian municipalities in order to identify political dynasties and measure fiscal outcomes at the municipality level. Specifically, we base our estimates on three different datasets: i) individual data about all local elected politicians in the period 1985-2012, which includes some biographical information (e.g., gender, education, date and place of birth, job); ii) local election outcomes in the period 1993-2012 (this dataset also includes data on all candidates for mayor); iii) a dataset about city fiscal outcomes

\footnotetext{
${ }^{5}$ Even though we do not use the threshold of 15,000 inhabitants as an identifying device in our analysis, in Section 5 we provide evidence that it is unlikely to affect our results.
} 
(revenues and expenditures) in the period 1998-2012. All data are publicly available and provided by the Italian Ministry of Interior for the above-mentioned periods.

Political dynasties are common at the municipal level in Italy. To identify dynastic politicians, we rely on the three datasets described above. Our data, however, do not allow us to directly identify family ties between elected representatives in Italy. Similar to recent studies on academic and political dynasties (Allesina (2011); Durante et al. (2011); Querubin (2013)) as well as inter-generational social mobility (Clark (2014); Clark and Cummins (2015)), we search for individuals with the same surname to identify (presumed) family ties. Specifically, we define dynastic mayors as those with at least one politician elected in the past (since 1985) in the same municipality with the same surname.

Using surnames to operationalize political dynasties is a valid approximation in our Italian setting, since children receive the surname of their father. However, such a methodology might suffer from two different types of errors. First, since people can have the same surname without being related, we might wrongly identify individuals from different families as dynastic. Second, this operationalization only identifies ties between family members if they have the same surname. While these reflect the closest family ties that are likely to generate the strongest effects (e.g., children, grandchildren), it may overlook more distant kinship ties (e.g., cousins, nephews, son-in-law) and those among spouses and daughters who have changed their surname upon marriage. Therefore we might wrongly identify as non-dynastic individuals who belong to the same family but have different surnames. Although data availability prevents us from directly addressing both issues, it is important to observe that they bias our estimates towards zero. Both issues indeed imply that we fail to define a certain number of dynastic politicians as part of a dynasty (i.e., these remain in the control, "non-dynastic" group). For instance, since dynastic politicians are expected to have different spending patterns than non-dynastic politicians, this misallocation pushes the average spending in the 'control' group closer to the average in the 'treatment' group (i.e., dynastic politicians) - inducing a bias in our estimates towards zero. This not only stacks the deck against us, but also implies that our findings reflect a lower bound of the true effect of political dynasties. Nonetheless, we further address this concern through several tests, such as excluding the most common surnames from the estimation 
sample and controlling for the relative frequency of each surname at the provincial level in the overall Italian population.

\section{Importance and characteristics of dynastic politicians}

\subsection{Share of dynastic politicians: heterogeneity across time and space}

Dynastic local politicians represent an important share of politicians. ${ }^{6}$ As shown in Figure 1a, the share of dynastic politicians by municipality over the period 1998-2012 is heterogeneously spread across the country: it seems to be particularly high in the south and north of the country (more than one politician in three has at least the same surname as a previous member of the city council), and lower in the center of the country (with shares closer to 10\%). However, the distribution in the shares of dynastic politicians during this period might reflect some underlying characteristics of the municipalities. For example, surname concentration is not even across the country. Using tax data (from 2005) that records the occurrence of every surname in the Italian population at the province level ${ }^{7}$, Figure 1bdisplays surname concentration at the province level. Surname diversity is very heterogeneous across Italian provinces, and higher in the north than the south (i.e., more individuals share the same surname in the south). In the north, the number of surnames corresponds to about $10-15 \%$ of the total number of individuals, while in the south this figure is about $5-10 \%$.

A second source of heterogeneity stems from the fact that the number of presumably dynastic individuals is not constant over time. Figure 2 highlights this heterogeneity overtime, representing the share of dynastic mayors for different categories of mayors, according to the frequency of their surnames in the total population. During our period of interest (1998-2012), the share of all dynastic mayors doubled, from $15 \%$ to more than $30 \%$. If we restrict the sample to individuals whose surname is not among the 100 most common surnames at the province level (which excludes about $15 \%$ of elected mayors), the share of assumed dynastic individuals increases from $13 \%$ in 1998 to $28 \%$ in 2012. For individuals whose surname is not among the 500 most common

\footnotetext{
${ }^{6}$ We use "politicians" to refer to members of municipality councils. Note that in this section, we mostly focus on dynastic politicians in the period 1998-2012, as our main analysis - on fiscal outcomes - is restricted to this period due to data availability.

${ }^{7}$ We are grateful to Giovanna Labartino for providing these data.
} 

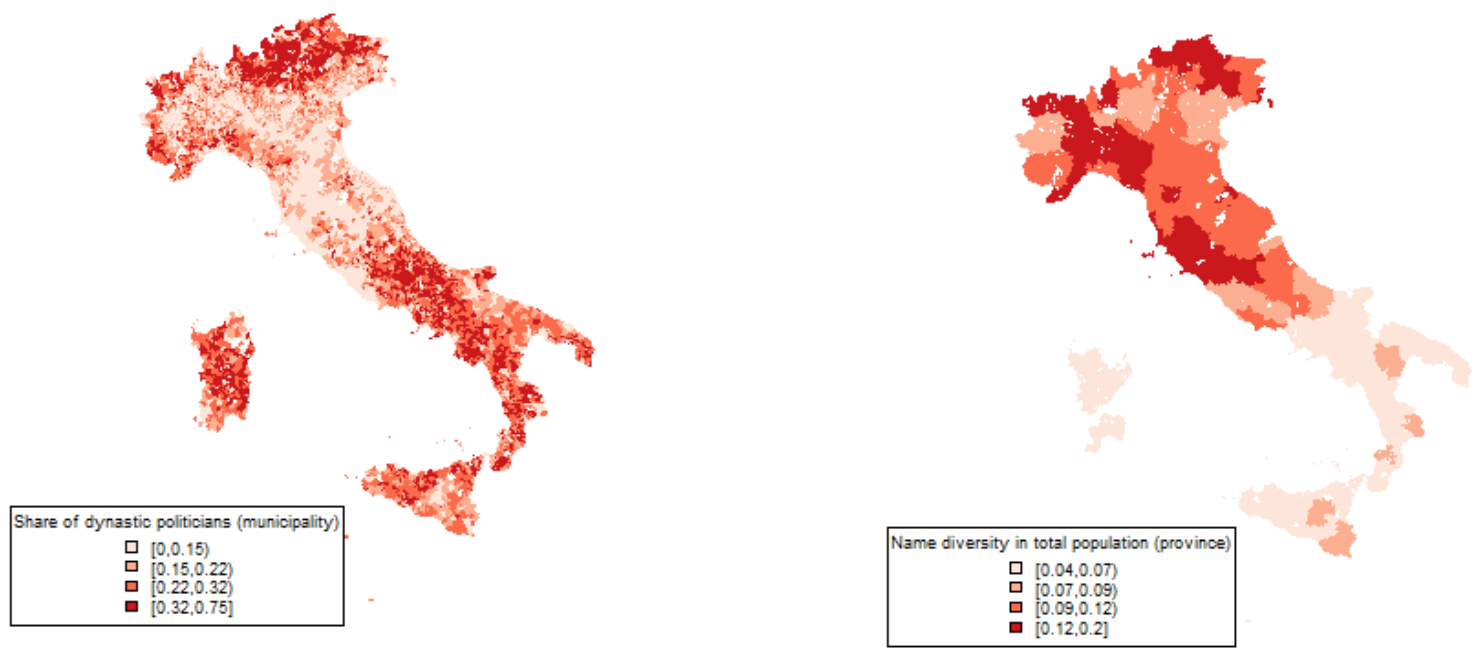

(a) Share of dynastic politicians at the city level (19982012)

(b) Surname diversity by province

Figure 1: Dynastic mayors and surname concentration

surnames at the province level (which excludes 20-25\%), this share rises from $11 \%$ in 1998 to $24 \%$ in 2012. Finally, for individuals whose surname is not among the $5 \%$ most common surnames in the province (which excludes about $50 \%$ of the sample), this share grows from $9 \%$ in 1998 to about $23 \%$ in 2012.

However, the huge increase in the number of dynastic candidates reflects the fact that for politicians elected in the later years of our dataset, a longer time window is available (i.e., all previous years in our dataset since 1985) to determine whether they are dynastic or not. This can be problematic because the number of dynastic individuals not identified as such is likely to decrease over time, which can induce a time-varying bias. $^{8}$

In order to address this issue, we provide alternative definitions of dynastic individuals, defining a mayor as dynastic if the first observed individual holding the same surname as him entered

\footnotetext{
${ }^{8}$ Moreover, in Web Appendix A, we show that the average age difference between first generations and their presumed dynastic successors increases over time (from about 8 years in 1998 to about 20 years in 2012). The distribution of age differences between the first individual of a dynasty (hereafter referred to as "first generation") and his potential successors during the period 1998-2012 is bimodal. The first mode is around 0 and the second is around 30. This evidence is compatible with the hypothesis that the kinds of linkages that we capture most often are either siblings or fathers and sons. Finally, even though our analysis starts in 1998, because of dataset limitations, we can assume that we are relatively more likely to catch sibling linkages at the beginning of the period, and relatively more likely to catch father-and-son linkages at the end of the period. See the Web Appendix for further details.
} 
Figure 2: Evolution of dynastic mayors and surname concentration

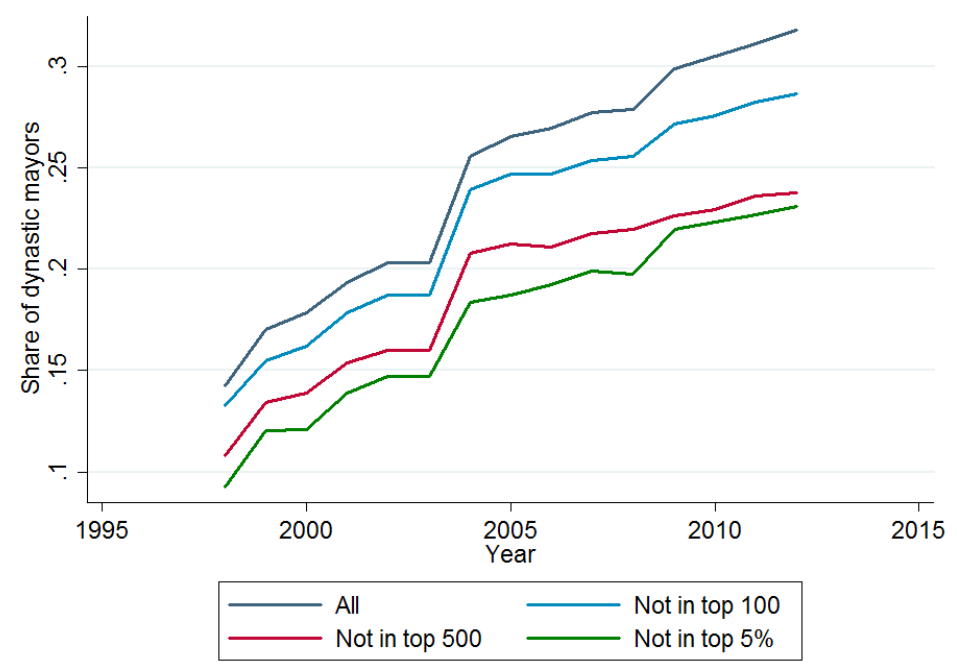

The figure represents the share of dynastic mayors for different subsamples, based on the frequency of their surname at the province level. The sample "Not in top 100" (resp. 500) includes all mayors whose surname is not among the 100 (resp. 500) most common in the province. The sample "Not in top 5\%" includes all mayors whose surname is not among the $5 \%$ most common surnames in the province.

the municipal council within 10 years or within 5 years before his first appearance in a municipal council. As emphasized in Figures $3 a$ and 3b, dynastic mayors identified within 10 years still correspond to more than $60 \%$ of the assumed dynastic individuals in 2012, while those identified within 5 years account for only $35 \%$ in that year.

Below, our benchmark results impose no restrictions, either in terms of politicians' surname frequency or the time window used to identify dynastic mayors: we use the full sample of politicians and identify dynastic individuals through shared surnames in the same city. However, we use the alternative specifications presented in this section to control for the robustness of the results.

\subsection{Characteristics of dynastic politicians}

In this section we provide a comprehensive set of results about the differences between dynastic and non-dynastic politicians. Using an RD strategy, we show that dynasties self-perpetuate in the political arena. We also find that dynastic candidates have longer political careers and are electorally more successful, as they are more likely to win local elections and to get elected in provincial/regional parliaments than their non-dynastic counterparts. 


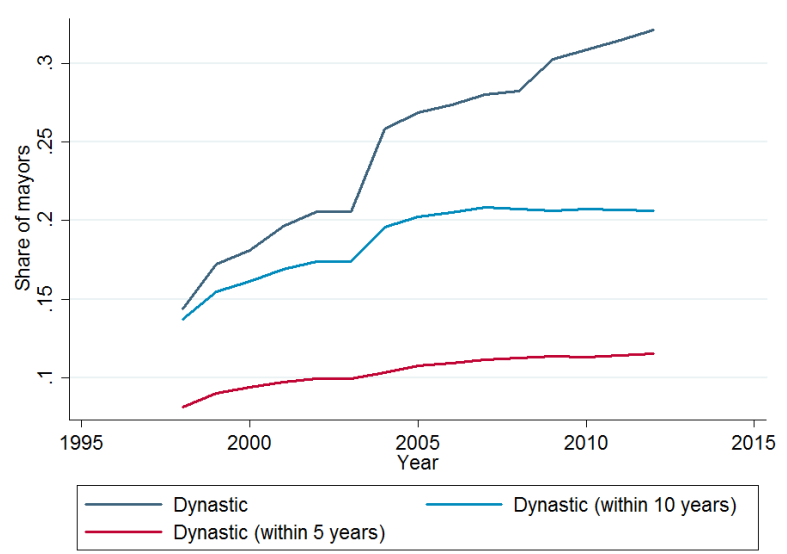

(a) Varying time windows

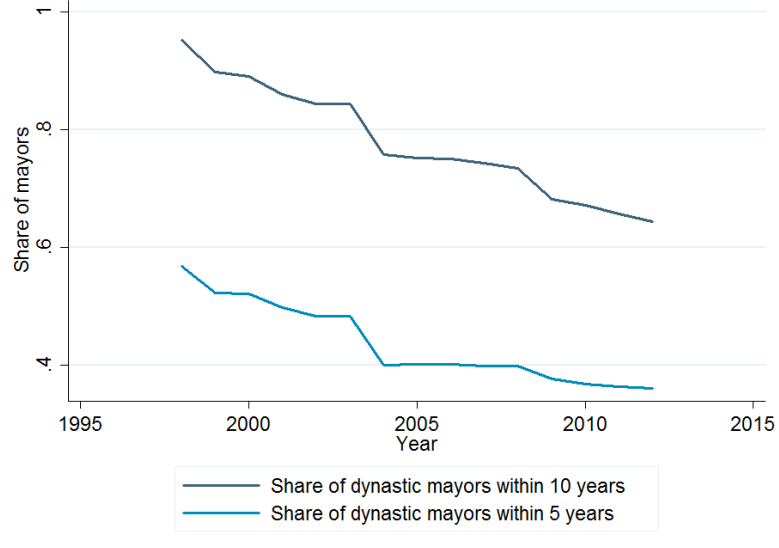

(b) Share of all dynastic mayors represented by dynastic mayors identified within 5- and 10-year windows

Figure 3: Dynastic mayors and time windows

\subsubsection{Descriptive statistics}

Table 1 shows the characteristics of dynastic mayors in cities between 1998 and 2012 (see the Appendix for the exact definition of each variable). Overall, dynastic mayors are younger, less likely to come from a right-wing party, are more educated and more likely to be born in the city they run than non-dynastic mayors. The proportion of women is also higher among dynastic mayors, as is the proportion of mayors representing a civic party (i.e., one that is not represented at the national level). Dynastic mayors are also much more common in the south of the country, and cities run by them are smaller but have much higher per capita budgets than those run by their non-dynastic peers. Cities run by dynastic mayors also have higher unemployment rates and lower levels of trust. We also find that the average term length for a dynastic mayor is slightly longer than for a non-dynastic mayor. Finally, we find slightly worse performance for dynastic mayors as measured by the share of actual revenues over expected revenues and the share of due expenditures paid during the year. However, as discussed more below, some of these facts are driven by structural effects.

\subsubsection{Members of political dynasties enter into politics at a younger age}

We also observe differences across dynastic and non-dynastic candidates. Indeed, even though we do not directly observe the characteristics of all candidates who ran for mayor between 1993 
Table 1: Characteristics of dynastic mayors

\begin{tabular}{|c|c|c|c|c|c|c|}
\hline Mayor characteristics & Non-Dynastic & Obs. & Dynastic & Obs. & Diff. & T-Stat \\
\hline Re-elected & $\begin{array}{c}0.551 \\
(0.497)\end{array}$ & 8,949 & $\begin{array}{c}0.581 \\
(0.494)\end{array}$ & 2,707 & -0.029 & -2.687 \\
\hline Age & $\begin{array}{l}51.123 \\
(9.422)\end{array}$ & 81,113 & $\begin{array}{c}47.915 \\
(10.016)\end{array}$ & 26,141 & 3.208 & 47.135 \\
\hline Male & $\begin{array}{c}0.913 \\
(0.282)\end{array}$ & 81,113 & $\begin{array}{c}0.898 \\
(0.303)\end{array}$ & 26,141 & 0.0148 & 7.262 \\
\hline Education & $\begin{array}{l}14.480 \\
(3.457)\end{array}$ & 79,651 & $\begin{array}{l}14.704 \\
(3.336)\end{array}$ & 24,790 & -0.224 & -8.999 \\
\hline Born in city & $\begin{array}{c}0.498 \\
(0.500)\end{array}$ & 81,113 & $\begin{array}{c}0.522 \\
(0.500)\end{array}$ & 26,141 & -0.025 & -6.958 \\
\hline Experience & $\begin{array}{l}11.948 \\
(6.662)\end{array}$ & 81,113 & $\begin{array}{l}7.180 \\
(5.137)\end{array}$ & 26,141 & 4.768 & 106.003 \\
\hline Civic & $\begin{array}{l}0.590 \\
(0.492)\end{array}$ & 81,113 & $\begin{array}{c}0.695 \\
(0.461)\end{array}$ & 26,141 & -0.104 & -30.332 \\
\hline \multicolumn{7}{|l|}{ City characteristics } \\
\hline South & $\begin{array}{c}0.273 \\
(0.446)\end{array}$ & 81,113 & $\begin{array}{c}.368 \\
(0.482)\end{array}$ & 26,141 & -0.095 & -29.281 \\
\hline Population & $\begin{array}{c}8,088.6 \\
(47,716.83)\end{array}$ & 79,371 & $\begin{array}{c}4,696.5 \\
(17,258.763)\end{array}$ & 25,625 & $3,392.1$ & 11.147 \\
\hline Unemployment & $\begin{array}{c}9.322 \\
(8.287)\end{array}$ & 80,780 & $\begin{array}{c}10.7340 \\
(9.115)\end{array}$ & 26,049 & -1.418 & -23.429 \\
\hline Trust & $\begin{array}{c}0.317 \\
(0.140)\end{array}$ & 70,906 & $\begin{array}{c}.312 \\
(0.145)\end{array}$ & 22,752 & .004 & 3.795 \\
\hline \multicolumn{7}{|l|}{ Average budget } \\
\hline Total exp. & $\begin{array}{c}1,582.137 \\
(2,445.329)\end{array}$ & 78,140 & $\begin{array}{c}1,889.501 \\
(11,281.407)\end{array}$ & 25,224 & -307.364 & -7.116 \\
\hline Current exp. & $\begin{array}{c}776.592 \\
(1,221.810)\end{array}$ & 78,140 & $\begin{array}{c}886.648 \\
(4,720.419)\end{array}$ & 25,224 & -110.056 & -5.931 \\
\hline Capital exp. & $\begin{array}{c}587.691 \\
(1,336.632)\end{array}$ & 78,143 & $\begin{array}{l}756.56855 \\
(6,403.512)\end{array}$ & 25,223 & -168.878 & -6.920 \\
\hline Tax rev. & $\begin{array}{c}346.746 \\
(587.284)\end{array}$ & 78,146 & $\begin{array}{l}382.70377 \\
(3,754.786)\end{array}$ & 25,247 & -35.958 & -2.581 \\
\hline Loans & $\begin{array}{c}138.074 \\
(397.479)\end{array}$ & 78,044 & $\begin{array}{c}160.904 \\
(2,287.443)\end{array}$ & 25,204 & -22.830 & -2.667 \\
\hline Capital Transfers & $\begin{array}{c}449.084 \\
(1,480.282)\end{array}$ & 78,037 & $\begin{array}{c}588.179 \\
(3,860.675)\end{array}$ & 25,218 & -139.095 & -8.344 \\
\hline \multicolumn{7}{|l|}{ Competence } \\
\hline Term duration & $\begin{array}{c}3.632 \\
(1.616)\end{array}$ & 22,337 & $\begin{array}{l}3.806 \\
(1.485)\end{array}$ & 6,859 & -0.174 & -7.963 \\
\hline Speed of payment & $\begin{array}{c}77.805 \\
(11.270)\end{array}$ & 76,622 & $\begin{array}{l}77.573 \\
(8.155)\end{array}$ & 24,500 & 0.232 & 2.985 \\
\hline Ability of revenue collection & $\begin{array}{c}61.545 \\
(15.919)\end{array}$ & 76,854 & $\begin{array}{c}60.768 \\
(16.614)\end{array}$ & 24,580 & 0.777 & 6.587 \\
\hline Growth of private tax base & $\begin{array}{c}0.022 \\
(0.524)\end{array}$ & 36,586 & $\begin{array}{c}0.014 \\
(0.142)\end{array}$ & 12,531 & 0.008 & 1.719 \\
\hline
\end{tabular}

The considered variables are: re-election rate, age, gender, level of education (as measured by the minimum number of years to obtain a certain degree), birthplace of the mayor, number of years since the first election to the city council, being a candidate of a civic party (the base category is being a candidate of a national political party), being elected in Southern Italy, city's population and unemployment rate, trust (at the provincial level), levels of total, current and capital expenditures, tax revenues, contracted loans and received capital transfers (all expressed in euros per capita), duration of the term, speed of payment, revenue collection capacity and yearly growth of the private tax base.

Standard deviations in parentheses. 
and 2012, we have data on those who were either elected mayor or who received enough votes to become a councilor. In the first two columns of Table 2, we predict the probability of being a dynastic candidate on several observable candidate characteristics using a linear probability model. In the first column, we consider the sample of all candidates for whom we have information. In the second column, we restrict the sample to elections for which information about at least the two best candidates is known. In all models, we include city and year fixed effects. In both specifications, we observe that the younger and less experienced candidates are more likely to be dynastic. Candidates with a lower level of education are also more likely to be dynastic, which is contrary to what is suggested in the descriptive statistics, which show that dynastic mayors tend to be more educated. Finally, dynastic candidates are more common among candidates who run a civic list, and among individuals born in the city. ${ }^{9}$

\subsubsection{Dynastic candidates are more likely to be elected}

Data about candidates also help us determine the extent to which having a family member in office helps win elections. The remaining columns of Table 2 use a linear probability model to predict dynastic candidates' probability of being elected. Specifically, Columns 3 and 5 consider all candidates in municipal elections between 1993 and 2012 for whom information was available. Columns 4 and 6 restrict the set of candidates to elections for which information about at least the two best candidates is known. All columns include city and year fixed effects;we also add to the previous set of control variables the number of candidates running for mayor. Columns 3 and 4 suggest that being a dynastic candidate has a positive impact on the probability of being elected (of about 3.5 percentage points). Moreover, this effect does not change when considering incumbent dynastic politicians (see the interaction Dynasty*Incumbent). The same does not hold concerning the interaction with experience (Columns 5 and 6): among candidates with at least one term of experience on the municipal council, dynastic candidates are not more likely to be elected, but among inexperienced candidates, they are 3-4 points more likely to be elected.

\footnotetext{
${ }^{9}$ Moreover, when interacting Age and Experience, we find not only that dynastic candidates are more likely than non-dynastic candidates to be young and inexperienced, but that they are also more likely to be young and experienced than young and inexperienced. In other words, it seems that dynastic individuals enter into politics at a younger age. These results are reported in the Web Appendix.
} 
Table 2: Characteristics and electoral performance of dynastic candidates

\begin{tabular}{|c|c|c|c|c|c|c|}
\hline & \multicolumn{2}{|c|}{ Dynasty } & \multicolumn{4}{|c|}{ Elected } \\
\hline & Unrestricted $+\mathrm{FE}$ & Restricted $+\mathrm{FE}$ & Unrestricted $+\mathrm{FE}$ & Restricted $+\mathrm{FE}$ & Unrestricted+FE & Restricted+FE \\
\hline Years of education & $\begin{array}{l}-0.000 \\
(0.63)\end{array}$ & $\begin{array}{l}-0.001 \\
(0.73)\end{array}$ & $\begin{array}{c}0.009 \\
(13.73)^{* * *}\end{array}$ & $\begin{array}{c}0.009 \\
(11.41)^{* * *}\end{array}$ & $\begin{array}{c}0.010 \\
(14.10)^{* * *}\end{array}$ & $\begin{array}{c}0.009 \\
(11.74)^{* * *}\end{array}$ \\
\hline Years of experience in council & $\begin{array}{c}-0.018 \\
(52.18)^{* * *}\end{array}$ & $\begin{array}{c}-0.019 \\
(47.89)^{* * *}\end{array}$ & $\begin{array}{c}0.010 \\
(24.98)^{* * *}\end{array}$ & $\begin{array}{c}0.010 \\
(22.11)^{* * *}\end{array}$ & & \\
\hline Male & $\begin{array}{l}0.006 \\
(0.75)\end{array}$ & $\begin{array}{l}0.006 \\
(0.67)\end{array}$ & $\begin{array}{c}0.054 \\
(7.20)^{* * *}\end{array}$ & $\begin{array}{c}0.062 \\
(7.15)^{* * *}\end{array}$ & $\begin{array}{c}0.060 \\
(7.95)^{* * *}\end{array}$ & $\begin{array}{c}0.068 \\
(7.82)^{* * *}\end{array}$ \\
\hline Age & $\begin{array}{c}-0.003 \\
(14.37)^{* * * *}\end{array}$ & $\begin{array}{c}-0.003 \\
(12.92)^{* * *}\end{array}$ & $\begin{array}{c}-0.003 \\
(13.69)^{* * *}\end{array}$ & $\begin{array}{c}-0.003 \\
(12.15)^{* * * *}\end{array}$ & $\begin{array}{c}-0.003 \\
(12.12)^{* * * *}\end{array}$ & $\begin{array}{c}-0.003 \\
(10.89)^{* * * *}\end{array}$ \\
\hline Born in City & $\begin{array}{c}0.089 \\
(17.21)^{* * *}\end{array}$ & $\begin{array}{c}0.090 \\
(16.09)^{* * *}\end{array}$ & $\begin{array}{c}0.027 \\
(5.07)^{* * *}\end{array}$ & $\begin{array}{c}0.029 \\
(4.73)^{* * *}\end{array}$ & $\begin{array}{c}0.030 \\
(5.72)^{* * *}\end{array}$ & $\begin{array}{c}0.032 \\
(5.19)^{* * *}\end{array}$ \\
\hline Civic & $\begin{array}{c}0.017 \\
(3.38)^{* * *}\end{array}$ & $\begin{array}{c}0.017 \\
(2.98)^{* * *}\end{array}$ & $\begin{array}{c}0.018 \\
(3.34)^{* * *}\end{array}$ & $\begin{array}{c}0.019 \\
(3.08)^{* * *}\end{array}$ & $\begin{array}{c}0.015 \\
(2.84)^{* * *}\end{array}$ & $\begin{array}{c}0.017 \\
(2.72)^{* * * *}\end{array}$ \\
\hline Surname frequency in province & $\begin{array}{c}0.273 \\
(14.82)^{* * *}\end{array}$ & $\begin{array}{c}0.287 \\
(13.89)^{* * *}\end{array}$ & $\begin{array}{l}0.000 \\
(0.03)\end{array}$ & $\begin{array}{l}0.004 \\
(0.20)\end{array}$ & $\begin{array}{l}0.003 \\
(0.20)\end{array}$ & $\begin{array}{l}0.006 \\
(0.33)\end{array}$ \\
\hline Incumbent & $\begin{array}{c}0.031 \\
(7.76)^{* * *}\end{array}$ & $\begin{array}{c}0.029 \\
(6.12)^{* * *}\end{array}$ & $\begin{array}{c}0.377 \\
(56.78)^{* * *}\end{array}$ & $\begin{array}{c}0.401 \\
(50.12)^{* * *}\end{array}$ & $\begin{array}{c}0.379 \\
(64.81)^{* * *}\end{array}$ & $\begin{array}{c}0.404 \\
(57.17)^{* * *}\end{array}$ \\
\hline Dynasty & & & $\begin{array}{c}0.035 \\
(5.53)^{* * *}\end{array}$ & $\begin{array}{c}0.035 \\
(4.68)^{* * *}\end{array}$ & $\begin{array}{l}0.001 \\
(0.07)\end{array}$ & $\begin{array}{l}0.002 \\
(0.15)\end{array}$ \\
\hline Dynasty*Incumbent & & & $\begin{array}{l}-0.006 \\
(0.50)\end{array}$ & $\begin{array}{r}-0.003 \\
(0.18)\end{array}$ & & \\
\hline Number of candidates & & & $\begin{array}{c}-0.054 \\
(30.86)^{* * *}\end{array}$ & $\begin{array}{c}-0.041 \\
(26.03)^{* * *}\end{array}$ & $\begin{array}{c}-0.054 \\
(30.75)^{* * *}\end{array}$ & $\begin{array}{c}-0.040 \\
(25.94)^{* * *}\end{array}$ \\
\hline No Experience & & & & & $\begin{array}{c}-0.146 \\
(25.82)^{* * *}\end{array}$ & $\begin{array}{c}-0.148 \\
(22.93)^{* * *}\end{array}$ \\
\hline Dynasty*No Exp & & & & & $\begin{array}{c}0.042 \\
(3.86)^{* * *}\end{array}$ & $\begin{array}{c}0.041 \\
(3.18)^{* * *}\end{array}$ \\
\hline$R^{2}$ & 0.34 & 0.35 & 0.20 & 0.16 & 0.20 & 0.17 \\
\hline$N$ & 63,352 & 51,215 & 63,352 & 51,215 & 63,352 & 51,215 \\
\hline
\end{tabular}

The table reports estimates from linear regressions. The outcome variable of Columns 1 and 2 is a dummy variable indicating whether a candidate is dynastic as a dependent variable. In Columns 3 to 6 , the outcome variable is a dummy indicating whether the candidate was elected. Columns 1, 3 and 5 consider all candidates in municipal elections between 1993 and 2012 for whom information was available. Columns 2, 4 and 6 restrict the set of candidates to elections for which information about at least the two best candidates is known. All specifications control for city and year fixed effects. Standard errors are clustered at the city level.T-Statistic in parentheses.

${ }^{*} p<0.1 ;{ }^{* *} p<0.05 ;{ }^{* * *} p<0.01$ 
Therefore, the dynastic advantage seems to somehow decrease depending on a candidate's level of political experience. This might be due to the fact that non-dynastic politicians also acquire some of the "inherited" skills over time. Finally, the probability of being elected does not depend on the frequency of the candidate's surname at the province level.

\subsection{Persistence of political dynasties}

Another important feature of political dynasties is that they seem to persist over time (Dal Bó et al. (2009) and Querubin (2013)). In this section, we illustrate two main channels of perpetuation. First, power seems to self-perpetuate, as elected individuals are more likely than nonelected individuals to have a relative in office in subsequent years. Second, dynastic politicians seem to have longer political careers at the municipal level than their non-dynastic counterparts.

\subsubsection{Intergenerational persistence}

Consistent with evidence from the literature (Dal Bó et al. (2009); Rossi (2016); Querubin (2013)), we find that power persists over time in Italian municipalities. To test for such persistence, we need to compare the probabilities that an elected candidate and a non-elected candidate will have a relative in office in subsequent years.

To do so, we use an RDD since it allows us to isolate a pure persistence effect from potentially unobserved factors that can determine both the probability that an individual will be elected and the probability that one of his relatives will be elected (such as charisma, competence or beauty, for example). ${ }^{10}$ In this framework, we compute the margin of votes for each candidate of each election. For the winner of the election, the margin corresponds to the difference between the share of votes he received and the share of votes received by his best challenger. For all losing candidates of an election, the margin corresponds to the difference between their share of votes and the share of votes received by the winner. This variable takes values between -1 and 1: a positive value indicates that the individual was elected mayor, while a negative value indicates that he was not elected. Furthermore, for each individual running for mayor between 1993 and

\footnotetext{
${ }^{10}$ We describe this empirical methodology below.
} 
2004, we indicate whether an individual with the same surname was elected mayor (or as a municipal councilor)within the 10 years after the election he ran in. ${ }^{11}$

Figure 4a shows that the average probability that an individual's relative will be elected mayor within 10 years increases with his margin of votes and is discontinuous around 0 : in other words, elected officials are more likely to subsequently have a relative in office than losing candidates. As the probability of having a relative elected within 10 years is discontinuously higher when the margin of votes is positive, to the extent that the margin of votes is continuous around zero ${ }^{12}$, a causal interpretation can be inferred. Figure $4 \mathrm{~b}$ shows that losing candidates are much less likely to have a relative elected to municipal office in the next 10 years (and much less so if they lost the election by a large margin), but that there is no discontinuity of this variable around the zero threshold. In other words, mayors who are elected by a narrow margin are not much more likely to have a member of their family elected to the municipal council within the next 10 years than candidates who narrowly lose.

In Web Appendix C, we present detailed results from an RDD between closely elected and closely non-elected individuals, which confirm that closely elected candidates are significantly more likely to have a relative elected mayor during the subsequent 10 years, but are not more likely to have a relative elected to the municipal council. While raw comparisons of means across elected and non-elected candidates suggest that elected candidates are almost twice as likely as non-elected candidates to have a relative elected mayor (3.8\% vs.2.2\%), the jump in the probability of a relative being elected mayor within 10 years at the zero cutoff is about 1 percentage point: this suggests that being elected mayor increases the probability of having a relative elected mayor by about $50 \% .{ }^{13} 14$

\footnotetext{
${ }^{11}$ We impose such a restriction because our sample of elections is from 1993 to 2014: therefore, for all elections during this time, a 10-year bandwidth ensures that the number of years considered after an election in the estimation is the same.

${ }^{12}$ Note that other covariates driving the electoral performance of dynastic individuals are also continuous around this threshold.

${ }^{13}$ Note that the results on perpetuation for mayors are likely to be biased downwards: indeed, because mayors usually stay in office for 4 or 8 years, the probability that someone from the same family will be elected within 10 years is estimated for only the last 2 to 6 years of the 10-year window. As we show in the Web Appendix , extending the estimation to the full sample of candidates between 1993 and 2014, and without imposing a 10-year bandwidth, does not change the results.

${ }^{14}$ The downward trend on the right-hand side of the graph about perpetuation in municipal councils is somewhat surprising: while individuals who lost elections by a large margin are very unlikely to later have relatives in the city council, we find that individuals who won by a large margin are less likely to have a relative in the city council than those who won by a narrow margin (yet we do observe a slightly upward perpetuation trend for the office of mayor). A potential explanation might be that mayors who have a strong grip on the city, and who want to transmit
} 


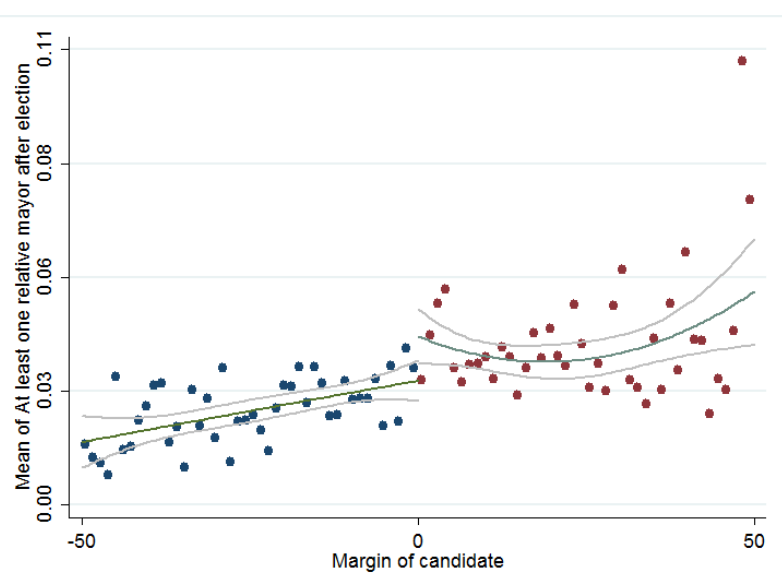

(a) Relatives elected mayor (within 10 years)

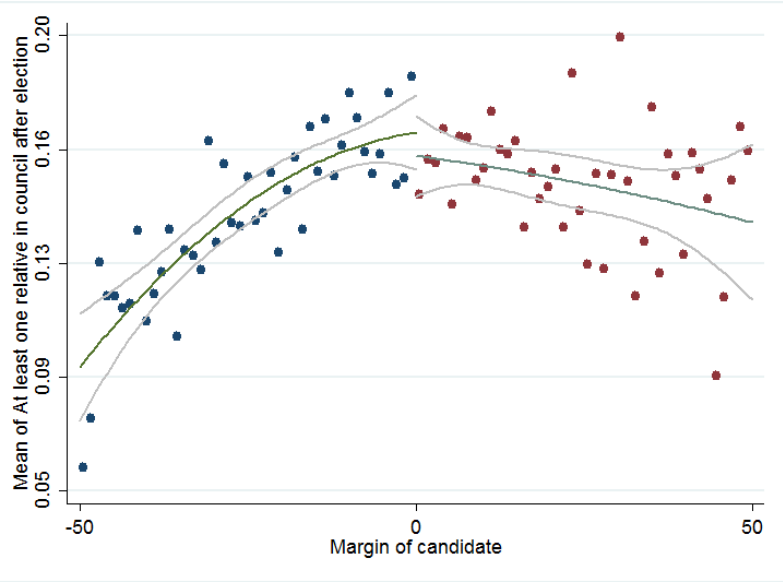

(b) Relatives elected to municipalcouncil (within 10 years)

Figure 4: Perpetuation of power -RD

\subsubsection{Longevity of dynastic politicians}

Not only is political power persistent over generations; elected individuals who come from political dynasties are also likely to serve longer on municipal councils. In Table 3, we regress the average length of term (in years) for each observed mayor or municipal council member on various characteristics. Column 1 includes all individuals, while Column 2 includes only those who first entered in politics in 1995 or after (in order to observe a longer period to determine their first election to a council ). As above, all specifications include city and year fixed effects. Overall, we find that the average number of years an individual spent in a municipal council is higher for dynastic individuals than for non-dynastic individuals (about two additional months).

Dynastic politicians have more successful careers not only in terms of duration but also in terms of climbing the political ladder: they are more likely to be elected to provincial or regional parliaments after serving on a municipal council. The results are reported in Columns 3 to 6 of Table 3. Using the same samples as previously, we define as a dependent variable a dummy equal to 1 if a municipal politician is later elected to the provincial or regional parliament (within the same region).

their power to their heirs, might have greater incentives to do so by helping them become mayor rather than a city councilor. 
Table 3: Longevity of politicians

\section{Longevity Provincial admin. Regional admin.}

Full+City FE Restricted+City FE Full+City FE Restricted+City FE Full+City FE Restricted+City FE

\begin{tabular}{lcccccc}
\hline Dynasty & 0.16407 & 0.09075 & 0.00087 & 0.00083 & 0.00073 & 0.00038 \\
& $(14.58)^{* * *}$ & $(8.59)^{* * * *}$ & $(2.27)^{* *}$ & $(1.96)^{*}$ & $(3.64)^{* * *}$ & $(1.80)^{*}$ \\
Age & -0.02854 & -0.01283 & -0.00037 & -0.00022 & -0.00017 & -0.00009 \\
& $(67.73)^{* * *}$ & $(30.12)^{* * *}$ & $(27.56)^{* * *}$ & $(12.33)^{* * *}$ & $(20.91)^{* * *}$ & $(8.83)^{* * *}$ \\
Years of education & 0.07696 & 0.02940 & 0.00160 & 0.00130 & 0.00048 & 0.00030 \\
& $(57.35)^{* * *}$ & $(20.35)^{* * *}$ & $(36.93)^{* * *}$ & $(22.52)^{* * *}$ & $(20.18)^{* * *}$ & $(11.31)^{* * *}$ \\
Male & 0.79149 & 0.49882 & 0.00738 & 0.00573 & 0.00161 & 0.00085 \\
& $(69.62)^{* * *}$ & $(44.30)^{* * *}$ & $(19.86)^{* * *}$ & $(14.04)^{* * *}$ & $(7.54)^{* * *}$ & $(3.85)^{* * *}$ \\
Born in city & 0.37530 & 0.22342 & 0.00197 & 0.00087 & 0.00025 & -0.00003 \\
& $(33.07)^{* * *}$ & $(18.58)^{* * *}$ & $(5.13)^{* * *}$ & $(1.70)^{* *}$ & $(1.15)$ & $(0.12)$ \\
Civic & -0.06426 & 0.04162 & -0.00295 & -0.00227 & -0.00062 & -0.00032 \\
& $(5.45)^{* * *}$ & $(3.35)^{* * *}$ & $(8.31)^{* * *}$ & $(4.79)^{* * *}$ & $(3.34)^{* * *}$ & $(1.38)$ \\
$R^{2}$ & 0.25 & 0.32 & 0.03 & 0.04 & 0.03 & 0.04 \\
$N$ & 548,828 & 291,980 & 548,828 & 291,980 & 548,828 & 291,980
\end{tabular}

The table represents estimates from linear regressions. In Columns 1 and 2, the term length of politicians (in years) in local municipal councils is the dependent variable. In Columns 3 and 4 , the dependent variable is a dummy variable indicating whether a municipal council or was later elected to a provincial parliament. In Columns 5 and 6 , the dependent variable is a dummy variable indicating whether a municipal councilor was later elected to a regional parliament. Columns 1,3 and 5 consider all members of city councils from 1985 to 2012. Columns 2, 4 and 6 restrict the sample to members of city councils who were appointed or elected after 1995. All specifications control for city fixed effects and year of election fixed effects. Standard errors are clustered at the city level. T-Statistic in parentheses.

${ }^{*} p<0.1 ;{ }^{* *} p<0.05 ; * * * p<0.01$ 
Only $1.4 \%$ of all observed members of municipal councils were subsequently elected to a provincial parliament (1\% for individuals elected or appointed after 1995), and about $0.4 \%$ of all observed members were part of a regional parliament $(0.3 \%$ for those elected or appointed after 1995). However, after controlling for year and city fixed effects and other individual characteristics, a dynastic politician has a higher probability than a non-dynastic politician of entering a provincial administration of about 0.08 percentage points in both the full and restricted samples (corresponding to about $6-8 \%$ of the sample average). For regional parliaments, the difference in probabilities corresponds to about 0.08 percentage points on the full sample, and 0.04 points on the restricted sample (which corresponds to approximately $15 \%$ and $20 \%$ of the sample average, respectively). ${ }^{15}$

\section{Consequences of political dynasties on local budgets}

The evidence presented above shows that dynastic politicians differ along several dimensions from non-dynastic politicians. Such differences might be linked to different behaviors while serving as mayor. In the next sections, we test this hypothesis.

\subsection{Panel regressions}

\subsubsection{Identification strategy}

To explore the effects of dynastic mayors on municipal budgets, we first use a fixed-effects approach. We are interested in two specific features: (1) the extent to which the size of the components of municipal budgets varies across dynastic and non-dynastic mayors and (2) the presence of PBCs at the municipality level, and their magnitude for dynastic vs. non-dynastic mayors. In each case, we use the mayoral two-term limit to isolate the potential effects of re-election incentives by interacting the variable of interest with a dummy indicating whether the mayor is in her first or second term. In our first strategy, we run fixed-effects panel regressions on the full sample of observations between 1998 and 2012.

\footnotetext{
${ }^{15}$ In a Web Appendix, we also document intergenerational persistence in terms of occupations, and find that the job category of a dynastic politician is very often similar to that of the first generation in the dynasty.
} 
Table 4: Year of election of mayors in the sample (1998-2012)

\begin{tabular}{c|cc|cc} 
& \multicolumn{2}{|c}{ Panel specification } & \multicolumn{2}{c}{ RDD specification } \\
Year & All obs. & Restricted & All obs. & Restricted \\
\hline 1999 & 4,312 & 3,855 & 976 & 918 \\
2000 & 841 & 605 & 126 & 101 \\
2001 & 1,182 & 880 & 305 & 261 \\
2002 & 891 & 586 & 269 & 221 \\
2003 & 437 & 260 & 132 & 119 \\
2004 & 4,202 & 3,660 & 1,230 & 1,126 \\
2005 & 811 & 607 & 132 & 105 \\
2006 & 1,178 & 902 & 396 & 347 \\
2007 & 870 & 655 & 300 & 257 \\
2008 & 500 & 358 & 175 & 145
\end{tabular}

The restricted samples are those used to estimate the PBCs. The panel specification includes all cities for which we observe two full terms after 1999. In the RDD specification, we include all elections for which information on the two best candidates is known, where at least one of them is dynastic and the subsequent term is complete (i.e., 5 years long).

We first test for the effect of dynastic mayors on average revenues and expenditures using the following specification:

$$
Y_{i t}=\alpha+\beta T L_{i t}+\delta D_{i t}+\kappa\left(D_{i t} * T L_{i t}\right)+\nu X_{i t}+\gamma_{t}+\epsilon_{i}+u_{i t}
$$

where $Y_{i, t}$ is an outcome variable for city $i$ in year $t, T L_{i t}$ is a dummy equal to 1 if the mayor is term-limited, $D_{i t}$ is a dummy equal to 1 if the mayor of city $i$ in year $t$ is dynastic, $X_{i t}$ is a set of city characteristics for city $i$ in year $t, \gamma_{t}$ is a year fixed effect, $\epsilon_{i}$ is a city fixed effect and $u_{i t}$ is a time-varying error term. The parameter $\delta$ indicates, for mayors who are not term limited, the difference in outcome variables between dynastic and non-dynastic mayors. The parameter $\kappa$ indicates the different effect of dynasty on non-term-limited vs. term-limited mayors. 
In a second specification, we test for the presence of stronger PBCs for dynastic mayors by estimating the following equation:

$$
\begin{aligned}
Y_{i t}= & \alpha+\beta T L_{i t}+\delta D_{i t}+\phi^{0} L Y_{i t} \\
& +\phi^{1}\left(D_{i t} * T L_{i t}\right)+\phi^{2}\left(L Y_{i t} * D_{i t}\right)+\phi^{3}\left(L Y_{i t} * T L_{i t}\right) \\
& +\phi^{4}\left(L Y_{i t} * T L_{i t} * D_{i t}\right) \\
& +\gamma X_{i t}+\gamma_{t}+\epsilon_{i}+u_{i t}
\end{aligned}
$$

where $L Y_{i t}$ is a dummy equal to 1 if the next election in city $i$ at time $t$ occurs during the following year and 0 otherwise. As this equation includes a triple interaction, we are interested in several parameters. First, the parameter $\phi^{0}$ indicates, for mayors who are not term limited and nondynastic, the difference in outcomes between the last year of the term and the first three years. The parameter $\phi^{2}$ indicates, for non-term-limited mayors, the extent to which this difference is higher for dynastic mayors than for non-dynastic mayors. The parameter $\phi^{3}$ indicates, for non-dynastic mayors, the extent to which the variation in the last year of the term is higher for term-limited than for non-term-limited mayors. Finally, the parameter $\phi^{4}$ indicates the extent to which the difference in PBCs between term-limited and non-term-limited mayors is higher for dynastic politicians. ${ }^{16}$

Note that we are able to identify PBCs because for each city, the electoral calendar is exogenously defined ex ante, and because municipal elections do not occur in the same year for each city. We are therefore able to separate year fixed effects from the effect of time until the next election. Furthermore, to make sure that we properly estimate PBCs, we only include cities that meet a certain number of criteria. In the fixed-effects estimation, we only include cities for which two full 5-year terms are observed (i.e., for elections occurring after 1999). This ensures that we avoid cases of early termination and that we have enough intra-city variation in terms of explanatory variables to separately identify all the effects mentioned above. ${ }^{17}$ Overall, this amounts to using

\footnotetext{
${ }^{16}$ As for the parameter $\phi^{1}$, it indicates whether during the three first years of a given term of a dynastic mayor, the outcome variable is higher under a term limitation.

${ }^{17}$ In the RDD framework implemented in the following sections, because the inference relies upon inter-city variation (as opposed to intra-city variation in the fixed-effect framework), we impose a slightly less stringent constraint and keep cities for which at least one full term is observed between 1999 and 2012.
} 
Table 5: Effect of political dynasties and term limits on average budget

\begin{tabular}{lcccccc}
\hline & Total exp & Current exp & Cap. exp & Tax rev & Loans & Cap. transfers \\
\hline Dynasty & 29.117 & 0.318 & 22.866 & 3.053 & 14.208 & 11.516 \\
& $(1.22)$ & $(0.06)$ & $(1.15)$ & $(1.28)$ & $(2.40)^{* *}$ & $(0.63)$ \\
TL & -6.233 & 4.536 & -13.383 & -0.939 & -1.659 & -7.193 \\
& $(0.54)$ & $(1.74)^{*}$ & $(1.36)$ & $(0.71)$ & $(0.54)$ & $(0.80)$ \\
Dynasty*TL & 1.095 & 12.797 & -0.312 & 1.134 & -17.097 & 4.473 \\
& $(0.04)$ & $(2.07)^{* *}$ & $(0.01)$ & $(0.37)$ & $(2.16)^{* *}$ & $(0.22)$ \\
$R^{2}$ & 0.02 & 0.24 & 0.02 & 0.42 & 0.01 & 0.01 \\
$N$ & 45,908 & 45,908 & 45,908 & 45,908 & 45,906 & 45,906 \\
\hline
\end{tabular}

The table presents estimates from fixed-effects panel regressions, using categories of public expenditures and income as dependent variables (all are expressed in euros per capita, and winsorized at the $1 \%$ level). The main explanatory variables are two dummies indicating (1) whether the mayor is dynastic and (2) whether he is term limited. The sample is comprised of all cities for which two full 5-year terms were observed between 1999 and 2012. Election years are excluded from the estimation. All specifications control for city and year fixed effects, as well as population size and the mayor's sex, age, experience, years of education and birthplace. Standard errors are clustered at the city level. T-Statistic in parentheses.

${ }^{*} p<0.1 ;{ }^{* *} p<0.05 ;{ }^{* * *} p<0.01$

a sample of 6,184 cities for the fixed-effects analysis (see Table 4 for the full list of elections by year). ${ }^{18}$ Finally, in order to avoid potential outliers, we winsorize the outcome data at the $1 \%$ level.

\subsubsection{Estimation}

Table 5 reports the estimation results for average budget components. The reported variables of interest are total expenditures, current expenditures, capital expenditures, taxes, loans, and capital transfers from the regional and national governments (expressed in euros per capita). Each regression controls for the mayor's age, experience and years of education. Covariates also include dummies indicating whether the mayor was born in the city, and whether she is from a civic party. Finally, we also control for the city's population.

In Table 5, we observe no effect of political dynasties on average current and capital expenditures. Nor do we find any effect on tax revenues and capital transfers from upper layers of government. However, it appears that dynastic mayors in their first term contract more loans (14 euros per capita, on average) than non-dynastic mayors in their first term. We also observe

\footnotetext{
${ }^{18}$ There are 2,938 cities in the RDD specification: the number of cities present in this specification is smaller as additional constraints to identify closely elected dynastic candidates are necessary (see next section).
} 
Table 6: Effect of political dynasties and term limits on PBCs

\begin{tabular}{lcccccc}
\hline & Total exp & Current exp & Capital exp & Tax rev & Loans & Cap. transfers \\
\hline Dynasty & 9.846 & -1.909 & 4.786 & 1.219 & 8.941 & -2.932 \\
& $(0.40)$ & $(0.37)$ & $(0.23)$ & $(0.51)$ & $(1.46)$ & $(0.15)$ \\
LY & 47.681 & -1.870 & 39.376 & -8.615 & 12.939 & 23.346 \\
& $(4.08)^{* * *}$ & $(1.10)$ & $(3.70)^{* * *}$ & $(8.02)^{* * *}$ & $(3.72)^{* * *}$ & $(2.45)^{* *}$ \\
TL & -3.537 & 3.831 & -10.887 & -3.083 & -0.774 & -4.617 \\
& $(0.28)$ & $(1.37)$ & $(1.02)$ & $(2.26)^{* *}$ & $(0.24)$ & $(0.47)$ \\
Dynasty* LY & 72.094 & 8.887 & 68.281 & 7.762 & 19.784 & 55.590 \\
& $(3.11)^{* * *}$ & $(2.97)^{* * *}$ & $(3.18)^{* * *}$ & $(3.63)^{* * *}$ & $(2.87)^{* * *}$ & $(2.84)^{* * *}$ \\
LY*TL & -8.052 & 2.897 & -7.732 & 8.367 & -2.851 & -8.881 \\
& $(0.50)$ & $(1.26)$ & $(0.53)$ & $(5.52)^{* * *}$ & $(0.61)$ & $(0.69)$ \\
Dynasty*TL & 13.762 & 13.375 & 15.288 & 2.311 & -11.763 & 19.634 \\
& $(0.49)$ & $(2.09)^{* *}$ & $(0.63)$ & $(0.75)$ & $(1.40)$ & $(0.89)$ \\
Dynasty*${ }^{*} Y^{*} \mathrm{TL}$ & -43.565 & -2.188 & -56.813 & -5.263 & -19.582 & -57.615 \\
& $(1.11)$ & $(0.45)$ & $(1.60)$ & $(1.50)$ & $(1.79)^{*}$ & $(1.84)^{*}$ \\
$R^{2}$ & 0.02 & 0.24 & 0.02 & 0.42 & 0.01 & 0.01 \\
$N$ & 45,908 & 45,908 & 45,908 & 45,908 & 45,906 & 45,906 \\
\hline
\end{tabular}

The table presents estimates from fixed-effects panel regressions, using categories of public expenditures and income as dependent variables (all are expressed in euros per capita, and winsorized at the $1 \%$ level). The main explanatory variables are three dummies indicating (1) whether the mayor is dynastic, (2) whether the mayor is term limited and (3) whether it is the last year in the mayor's term. All outcome variables are expressed in euros per capita. The sample is comprised of all cities for which two full 5-year terms were observed between 1999 and 2012. Election years are excluded from the estimation. All specifications control for city and year fixed effects, as well as population size and the mayor's sex, age, experience, years of education and birthplace.Standard errors are clustered at the city level. T-Statistic in parentheses.

${ }^{*} p<0.1$; $^{* *} p<0.05 ;{ }^{* * *} p<0.01$

that dynastic term-limited mayors contract far fewer loans than their non-dynastic counterparts (about 17 euros per capita less).

But while few effects are noticeable in terms of average budget, we find much more variation in terms of PBCs. Several conclusions can be drawn from the analysis of Table 6. First, in cities run by non-dynastic mayors in their first term, expenditures are about 48 euros per capita higher in the last year of the term than at the beginning. This is mainly due to an increase in capital expenditures (which are 39 euros per capita higher), which seems to be financed by an increase in capital transfers from the government and the region (with a difference of about 23 euros per capita between the last year and the three first years of the term) and by an increase in contracted loans (with a difference of about 13 euros per capita). However, tax revenues seem to decrease during the last year of the term byabout 10 euros. Put differently, we observe a strong PBC in our sample: before the elections, non-dynastic and non-term-limited mayors increase capital expenditures and reduce taxes, while increasing loans and transfers from upper levels of government. 
Second, among mayors who are not term limited, PBCs are much higher for dynastic mayors. Indeed, between the last year and the previous 3 years of the first term, the variation in total per capita expenditures of non-term-limited mayors is 72 euros higher for dynastic than for non-dynastic mayors. This higher PBC comes mostly from a substantial additional increase in capital expenditures during the last year of the term (68 additional euros compared to the three 3 years), and from an additional increase in current expenditures per capita (about 9 euros). This increase in expenditures during the last year of the term is mostly financed by capital transfers from the national and regional governments (with an additional difference of 55 euros between the last year and the first 3 years of the term) and by an increase in contracted loans (with an additional difference of 20 euros), while taxes increase by an additional 7 euros during the last year (meaning that in absolute terms, non-term-limited dynastic mayors do not increase taxes during the last year of their term). Therefore, the PBC of dynastic mayors in their first term is much more pronounced than that of non-dynastic mayors in their first term: they spend relatively much more at the end of the term than non-dynastic mayors, and finance this additional increase in expenditures mostly through capital transfers from the national and regional governments. The magnitude of the effect is sizable, as the increase in total expenditures of dynastic mayors is $50 \%$ higher than the increase in total expenditures of non-dynastic mayors, while it is $75 \%$ higher for capital expenditures, $53 \%$ higher for loans and $138 \%$ higher for capital transfers. The relative increase in expenditures and revenues of dynastic mayors prior to the election represents an increase of $6 \%$ of a standard deviation in total expenditures, $8 \%$ of a standard deviation in capital expenditures, $9 \%$ of a standard deviation in loans and $7 \%$ of a standard deviation in capital transfers.

A third conclusion from this table is that PBCs are not markedly different between term-limited and non-term-limited non-dynastic mayors. Except for taxes, which are relatively higher at the end of the term for term-limited mayors, we find no significant difference in the evolution of other variables.

However, we observe a difference in PBCs between non-term-limited and term-limited dynastic mayors: compared to non-dynastic mayors in their second term, dynastic term-limited mayors seem to reduce expenditures, loans and capital transfers at the end of their term more than their counterparts. Though we observe significant coefficients (at the $10 \%$ level) only for loans 
and capital transfers, the magnitude of these negative coefficients (Dynasty ${ }^{*} Y^{*} T L$ ) is similar to the magnitude of the positive coefficients indicating the relative PBCs of non-term-limited dynastic mayors (Dynasty ${ }^{*} Y$ ). This finding suggests that term-limited dynastic mayors do not have stronger PBCs than non-dynastic, term-limited mayors.

\subsection{Matching on discontinuity}

\subsubsection{The RDD setting}

Even though the electoral schedule is exogenous, the effects identified in the panel regressions might be biased if unobserved mayor and city characteristics are correlated with both dynasty and the outcome. This could happen, for example, if voters chose their candidate depending on criteria that affect both the probability of having a dynastic mayor and the policies implemented. In addition, if the probability of electing dynastic candidates is affected by policy outcomes or the PBC, then our estimated effect might be biased.

To address these issues, we use an RDD, focusing on close elections in which the two best candidates are a dynastic and a non-dynastic one. We define the forcing variable as the difference in vote shares between the best dynastic candidate and the best non-dynastic candidate. This variable can take any value between -1 and 1 , and it takes a positive value if a dynastic mayor is elected. The intuition behind this methodology is that the assignment of dynastic or nondynastic mayors in elections won by a narrow margin is as good as random. Our setting involves a sharp RDD. $D_{i}$ is the dummy variable indicating whether a dynastic mayor is elected, and $X_{i}$ denotes the margin of the best dynastic candidate. In this case, we have:

$$
D_{i}=\mathbf{1}\left[X_{i}>0\right]
$$

Assuming that the threshold cannot be manipulated (i.e., that the forcing variable is not discontinuous around the threshold of 0 ), and that there exists no discontinuity in other potential confounding factors around the threshold, we can estimate the effect of dynasty as a local average treatment effect (LATE), which corresponds to the discontinuity of the observed variable at 
the threshold. Denoting $Y_{i}(0)$ as the outcome variable of a city not run by a dynastic mayor and $Y_{i}(1)$ as the outcome variable of a city run by a dynastic mayor, we seek to estimate the following LATE at the threshold $X_{i}=0$ :

$$
\beta=\mathbf{E}\left[Y_{i}(1)-Y_{i}(0) \mid X_{i}=0\right]
$$

Such an estimate can be found by running the following regression:

$$
Y_{i t}=\alpha+\beta D_{i t}+\delta P\left(X_{i t}\right)+\gamma P\left(X_{i t}\right) D_{i t}+\epsilon_{i t}
$$

where $Y_{i t}$ is the outcome of interest in city $i$ over the term $t, D_{i t}$ is a dummy equal to 1 if the elected mayor is dynastic and $P\left(X_{i t}\right)$ is a polynomial function of the mayor's margin of victory. The estimated effect of dynastic mayors is therefore the coefficient $\hat{\beta} .{ }^{19}$

However, as pointed out by Hahn et al. (2001) and summarized by Lee and Lemieux (2010), in order for the observations below the threshold to be a good counterfactual of individuals on the right of the threshold, and for the estimate $\hat{\beta}$ to be unbiased, the potential outcomes $\mathbf{E}\left[Y_{i}(1) \mid X\right]$ and $\mathbf{E}\left[Y_{i}(0) \mid X\right]$ must be continuous around the threshold. This implies that if some control variables correlated with the outcome variable are also discontinuous around the threshold, the estimated local treatment effect is likely to be biased. Below, we show that this is precisely what is happening in our setting.

\subsubsection{The limitations of RD in our setting}

As explained above, the RD provides unbiased estimates of the treatment if the threshold of the forcing variable cannot be manipulated. This amounts to testing whether the running variable is continuous around the threshold. To check the validity of this hypothesis in our framework,

\footnotetext{
${ }^{19}$ As in the fixed-effect estimation, we include only full 5-year terms after 1999, and exclude election years from the estimation.
} 
Figure 5: McCrary test on the RDD sample of municipal elections

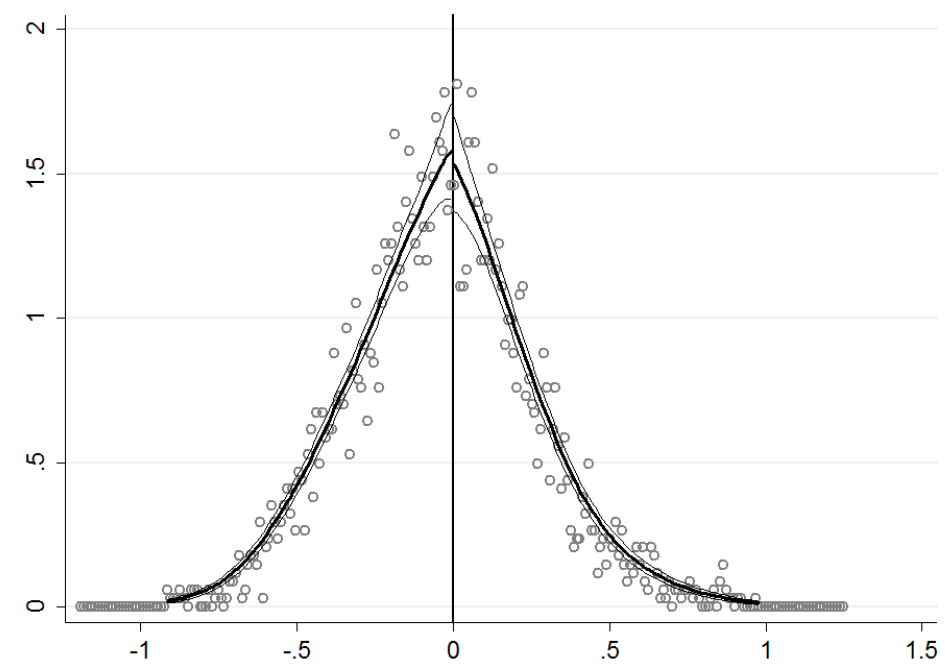

The figure represents a McCrary test of discontinuity in zero of the density of the margin of the best dynastic candidates for our selected sample of elections between 1999 and 2007

we run a McCrary test (McCrary (2008)), the results of which are presented in Figure 5. To identify the margin of dynastic and non-dynastic candidates, we only kept elections for which information on at least the two best candidates is available, and in which at least one dynastic candidate was identified. As previously explained, we only present results for cities for which full 5-year terms are observed (the number of elections meeting these criteria is presented in Table 4 above). The test suggests that the margin of dynastic candidates on the panel of elections we consider does not seem to be discontinuous around zero.

Another key hypothesis of the RDD is that around the threshold, the allocation of the treatment (i.e., having a dynastic mayor or not) should be as good as random. Put differently, we should not observe any significant discontinuity around the threshold for other covariates. However, as emphasized in Figure 6, age and experience are markedly lower for dynastic mayors. As shown in Figure 7, the main other control variables are mostly balanced around the threshold (except for the mayor's birthplace, as dynastic mayors are more likely to be born in the city). Table 7 confirms this intuition: it gathers results from the estimation of an RD in which we estimate a local polynomial regression with polynoms of order 1, using an optimal bandwidth selected according to the methodology developed by Calonico et al. (2014) and a uniform kernel. ${ }^{20}$

\footnotetext{
${ }^{20}$ The results are similar when controlling for a higher order of the polynoms.
} 

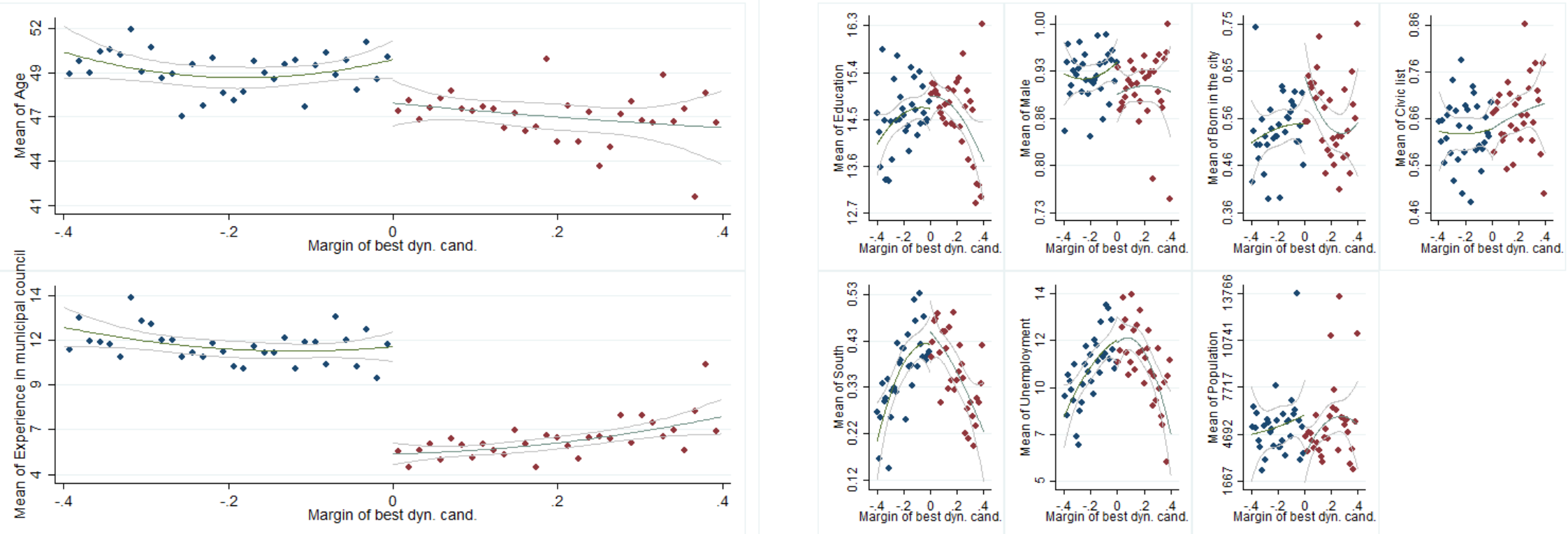

Figure 6: Discontinuity of age and experience (full sample)
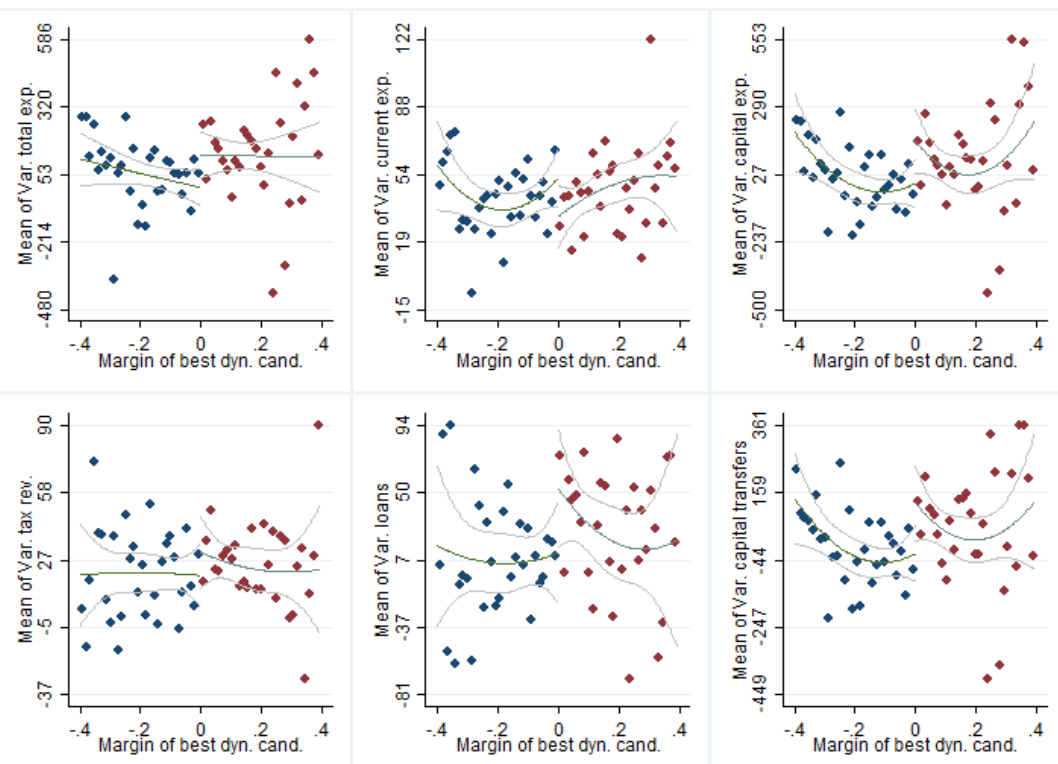

Figure 8: Variation in expenditures and revenues (first term)

Figure 7: Discontinuity of other variables (full sample)
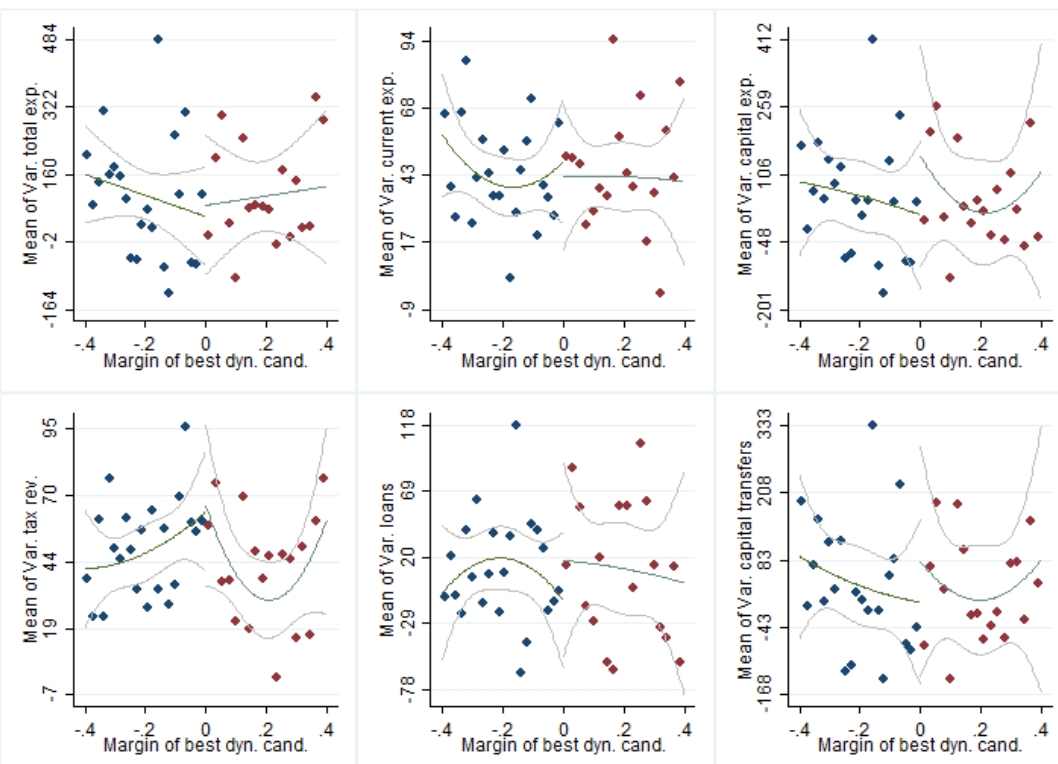

Figure 9: Variation in expenditures and revenues (second term) 
Table 7: Discontinuity of covariates around the threshold

\begin{tabular}{lccccc}
\hline & Age & Exp & Born same city & Sex & Education \\
\hline Dynasty & -2.547 & -6.086 & 0.092 & -0.040 & 0.443 \\
& $(2.78)^{* * *}$ & $(11.38)^{* * *}$ & $(1.90)^{*}$ & $(1.49)$ & $(1.33)$ \\
Bandwidth & 0.19 & 0.17 & 0.16 & 0.15 & 0.16 \\
$N$ & 1,854 & 1,668 & 1,646 & 1,550 & 1,560 \\
\hline \multirow{2}{*}{ Dynasty } & Civic & Reg South & Pop & Unemployment & \\
& 0.017 & 0.008 & -634.953 & -0.174 & \\
$R^{2}$ & $(0.36)$ & $(0.19)$ & $(0.46)$ & $(0.22)$ & \\
$N$ & 0.17 & 0.21 & 0.12 & 0.18 & \\
\hline
\end{tabular}

The table presents the results of an RD estimation with an optimal bandwidth calculated using the Calonico et al. (2014) method, which employs uniform bandwidth and controls for an order-one polynom of the margin of victory of the best dynastic candidate. Dependent variables are characteristics of mayors and their cities. The sample consists of all full 5-year mayoral terms for election years between 1999 and 2012. Age corresponds to the age of the mayor during the middle of his term, and experience corresponds to the mayor's experience at the beginning of the term. Standard errors clustered at the city level. T-Statistic in parentheses.

${ }^{*} p<0.1 ;{ }^{* *} p<0.05 ;{ }^{* * *} p<0.01$

Errors are clustered at the municipal level. Overall, around the threshold, dynastic mayors are 2.5 years younger, have spent 6 years less in the municipal council (which corresponds to more than a term of difference) and are 10 percentage points more likely to be born in the city than non-dynastic mayors. ${ }^{21} 22$

Given these discontinuities in observed covariates, which are likely to have an impact on PBCs (Alesina et al. (2015) show, for example, that young mayors in Italian municipalities have higher PBCs), the potential outcomes are likely to be discontinuous, and the estimation of the causal effect of dynastic leadership on PBCs might be biased. However, while in such a setting the RD results cannot be said to indicate the pure effect of electing a dynastic mayor, provided that the running variable is continuous around the zero cutoff (so that in very close races, observable characteristics are unlikely to determine who is elected), they still indicate the type of policies

\footnotetext{
${ }^{21}$ While these results are consistent with those presented in Section 3, they cannot be interpreted as showing that voters favor dynasty over age and experience, and that electing a young and inexperienced mayor is therefore a consequence of electing a dynastic mayor. In fact, we find that in close elections between old and young candidates, closely elected younger mayors are disproportionately more likely to be dynastic. Similarly, closely elected inexperienced candidates are more likely to be dynastic (results available upon request).

${ }^{22}$ Moreover, note that the concern that our dynastic measure mostly captures politicians sharing the same surname instead of real family ties is dismissed by the strong discontinuities of age and experience, which confirm the fact that we are identifying two groups of individuals (dynastic and non-dynastic) with different characteristics.
} 
implemented by a certain type of politician, who would be dynastic, young and with little political experience. ${ }^{23}$

We therefore show, as an indicative benchmark, the extent to which outcome variables are discontinuous around the threshold. We report only graphs and results concerning the PBCs, and show the outcomes on average spending - which are similar to the fixed-effects estimations - in the Web Appendix.

Figures 8 and 9, respectively, report the differences in expenditures and revenues between the last year of the term and the average of the previous years, as a function of the margin of the best dynastic candidate, for mayors in their first and second terms. The results suggest that the variation in total expenditures, capital expenditures and capital transfers is clearly discontinuous at the threshold, and markedly higher for dynastic mayors. However, this appears true only for mayors in their first term.

Table 8 , which reports estimates of the discontinuity of these different variables at the threshold (following the same methodology as the one used for the covariates), confirms the graphical representation: total expenditures, capital expenditures and capital transfers per capita increase much more during the last year of the term for dynastic mayors who can run for re-election. Specifically, the difference in variation between dynastic and non-dynastic mayors is about 212 euros per capita for capital expenditures and about 210 euros per capita for capital transfers. While these coefficients are much higher than in the fixed-effects specification, we cannot compare them directly, as the selected samples are different.

Despite the clear discontinuities of outcome variables around the threshold, the fact that dynastic mayors are significantly younger and less experienced around the threshold prevents us from estimating the pure causal effect of dynasty. However, in this framework, controlling for observed covariates is unlikely to help us identify the pure effect of political dynasties. As emphasized by Calonico et al. (2016), controlling for observed covariates helps improve the consistency of the estimation only if the continuity of the potential outcome is likely to hold. These authors further argue that controlling for interactions between covariates and treatments is likely to improve the consistency of the estimation only in very restrictive situations. Nevertheless, the

\footnotetext{
${ }^{23}$ We therefore embrace the points of view of Becker et al. (2016), Campa and Serafinelli (2015) and Gagliarducci and Paserman (2016), who discuss RDD results in a similar fashion.
} 
Table 8: Discontinuity of PBCs

Without Covariates

\begin{tabular}{lcccccc}
\hline No Term Limit & $\Delta$ Total exp & $\Delta$ Current exp & $\Delta$ Capital exp & $\Delta$ Tax rev & $\Delta$ Loans & $\Delta$ Transfers \\
\hline Dynasty & 198.201 & -15.946 & 212.507 & 11.501 & 51.512 & 210.463 \\
& $(2.39)^{* *}$ & $(1.24)$ & $(2.69)^{* * *}$ & $(0.96)$ & $(1.77)^{* *}$ & $(3.16)^{* * *}$ \\
Bandwidth & 0.13 & 0.11 & 0.13 & 0.14 & 0.13 & 0.13 \\
$N$ & 955 & 864 & 947 & 1,047 & 966 & 991 \\
\hline Term Limit & $\Delta$ Total exp & $\Delta$ Current exp & $\Delta$ Capital exp & $\Delta$ Tax rev & $\Delta$ Loans & $\Delta$ Transfers \\
\hline Dynasty & 94.450 & -4.737 & 95.119 & -9.538 & 58.669 & 74.563 \\
& $(0.57)$ & $(0.28)$ & $(0.59)$ & $(0.53)$ & $(1.22)$ & $(0.58)$ \\
Bandwidth & 0.20 & 0.17 & 0.21 & 0.20 & 0.19 & 0.22 \\
$N$ & 464 & 384 & 483 & 462 & 426 & 508 \\
\hline
\end{tabular}

With Covariates

\begin{tabular}{lcccccc}
\hline No Term Limit & $\Delta$ Total exp & $\Delta$ Current exp & $\Delta$ Capital exp & $\Delta$ Tax rev & $\Delta$ Loans & $\Delta$ Transfers \\
\hline Dynasty & 215.278 & -12.927 & 220.169 & 13.338 & 66.003 & 213.825 \\
& $(2.40)^{* *}$ & $(0.94)$ & $(2.60)^{* * *}$ & $(1.07)$ & $(2.17)^{* *}$ & $(3.00)^{* * *}$ \\
Bandwidth & 0.13 & 0.11 & 0.13 & 0.14 & 0.13 & 0.13 \\
$N$ & 928 & 841 & 921 & 1,017 & 938 & 961 \\
\hline Term Limit & $\Delta$ Total exp & $\Delta$ Current exp & $\Delta$ Capital exp & $\Delta$ Tax rev & $\Delta$ Loans & $\Delta$ Transfers \\
\hline Dynasty & 89.683 & -13.124 & 92.717 & -10.509 & 71.187 & 89.875 \\
& $(0.52)$ & $(0.75)$ & $(0.54)$ & $(0.57)$ & $(1.47)$ & $(0.65)$ \\
Bandwidth & 0.20 & 0.17 & 0.21 & 0.20 & 0.19 & 0.22 \\
$N$ & 452 & 376 & 471 & 450 & 416 & 496 \\
\hline
\end{tabular}

The table presents the results of an RD estimation with an optimal bandwidth calculated using the Calonico et al. (2014) method, which employs uniform bandwidth and controls for an order-one polynom of the margin of victory of the best dynastic candidate. Dependent variables are the differences of categories of expenditures and revenues between the last year and the average of the first 3 years, winsorized at the 1\% level. The sample consists of all full 5-year mayoral terms, for election years between 1999 and 2012 . Regressions are run separately on the sample of term-limited and non-term-limited elected mayors. Covariates include experience, age, place of birth, sex and years of education of the mayor, population and unemployment in the city, as well as dummies indicating whether the mayor is from a civic party and whether the city is in the South of the country. Standard errors clustered at the city level. T-Statistic in parentheses.

${ }^{*} p<0.1 ;{ }^{* *} p<0.05 ;{ }^{* * *} p<0.01$ 
second panel of Table 8 shows that including control variables in the estimation does not seem to affect our estimates.

To partially recover the causal effect of dynastic mayors, we complement this RD with a matching procedure that helps reduce the observed imbalances around the threshold, i.e.,it controls for differences in age and experience between dynastic and non-dynastic mayors. ${ }^{24}$

\subsubsection{Matching on discontinuity: estimation strategy}

In order to disentangle the effects of dynasty from the those of age and experience, we use a method of matching on discontinuity to control for the impact of potential confounding factors, while still exploiting the strict treatment assignment provided by the threshold of the forcing variable. In the spirit of Alesina et al. (2015), we assume that for observations with values of $X_{i}$ located in $]-b, b[$, if the following two conditions hold, then we can provide an unbiased estimate of the treatment (namely, the fact of having a dynastic mayor):

$$
\begin{array}{r}
Y_{i}(0), Y_{i}(1) \perp D_{i} \mid Z_{i} \\
0<P\left(D_{i}=1 \mid Z_{i}\right)<1,
\end{array}
$$

where $Y_{i}(0)$ and $Y_{i}(1)$ are, respectively, the potential outcomes of non-dynastic and dynastic mayors, $D_{i}$ is the dummy variable indicating whether mayor $i$ is dynastic or not, and $Z_{i}$ represents the set of observed covariates we control for.

The first condition states that electing a dynastic mayor is independent of the potential outcomes of the election, conditional on other covariates. If this hypothesis is satisfied, this controls for the potential biases induced by the discontinuity of confounding factors around the threshold. The second condition simply states that for any set of observed characteristics, there exists a common support so that we can observe both treated and untreated individuals.

\footnotetext{
${ }^{24}$ More generally, while the RDD framework is useful for causal inference, it might not be suitable for drawing general conclusions: indeed, the nature of the design imposes the estimation to be made on observations with a high level of political competition, and does not allow us to generalize to a less competitive framework.
} 
These hypotheses are strong, as this methodology enables us to estimate a causal effect of political dynasty only to the extent that observable characteristics account for all of the selection bias. Put differently, our results can have a causal interpretation only if we consider that comparing dynastic and non-dynastic mayors with the same observable characteristics is enough to control for selection effects.

In our estimation, we provide results for different bandwidths around the forcing threshold: in order to check that the results are not specific to our choices of bandwidths, we report the results for 10 different bandwidths ranging from $4-40 \%$ (in absolute value around the zero threshold). Note that the results for smaller bandwidths are more likely to reveal causal effects, as they rely on closer elections, in which unobserved selection into dynastic mayors is less likely to occur. On the contrary, the results obtained for non-close elections are more general but less likely to be causal. As in the previous paragraph, we focus on the effects of PBCs and report the estimates on average spending in the Web Appendix. ${ }^{25}$ We use propensity score matching on all the observable variables studied above to control for confounding factors. In order to ensure a balance between the matched treated and untreated observations, we match each dynastic mayor with his closest counterpart among non-dynastic mayors, discarding potential matches located outside of a 0.2-standard-deviation caliper. ${ }^{26}$

\subsubsection{Estimation}

We first begin by showing that our estimation strategy actually reduces imbalances between the matched dynastic and non-dynastic mayors. For ease of exposition, we only consider mayors in their first term, and report only the reduction of imbalances in terms of age and experience. ${ }^{27}$ As in the RDD, we consider only full terms after 1999. Table 9 presents the results for 10 different bandwidths around the threshold. As suggested by the table, our matching methodology re-

\footnotetext{
${ }^{25}$ In this estimation, we do not apply the optimal bandwidths computed in the RDD setup, as they depend on the outcomes variables, while it is generally acknowledged that matching procedures and reduction in imbalances should not depend on the outcome variable. As a consequence, the balance checks presented below hold for all the considered outcomes variables.

${ }^{26}$ Note that the results also hold when we allow for multiple matching, where, for example, we associate each dynastic mayor with his three closest non-dynastic counterparts. Generally speaking, the choice of the number of neighbors comes from a trade off between bias and variance: increasing the number of matched pairs increases the amount of treated information (thus potentially increasing the accuracy of the estimated treatment effect), but increases the average distance between the compared treated and untreated units (thus potentially increasing the bias).

${ }^{27}$ Balance checks for mayors in their second term are presented in a Web Appendix.
} 
duces the imbalances on age and experience for all the reported bandwidths. We also report the smallest $\mathrm{p}$-value among all the T-tests of differences between dynastic and non-dynastic mayors, ran on nine of our covariates on both matched and unmatched samples. Overall, we observe that the minimum p-value among all the tests is systematically greater in the matched sample than in the unmatched sample. This suggests that our matching methodology successfully reduces the most important imbalances. Furthermore, out of our 10 matched samples, the smallest p-value is greater than $5 \%$ in six cases, and out of the 90 T-tests we ran on the matched samples, we found significant differences in only five cases. Therefore, while drastically reducing the imbalances in terms of age and experience, our matching methodology does not seem to create imbalances on other variables. ${ }^{28}$

The results of our estimations for mayors in their first and second terms are presented in Figures 10 and 11, respectively. The graphs present the average treatment on the treated (ATT) - i.e., the effect estimated on cities that were run by a dynastic mayor, with $10 \%$ confidence intervals. In line with previous results, we find that eligible dynastic mayors increase significantly more than non-dynastic mayors their capital (and therefore total) expenditures during the last year of their term, financing it mostly through higher transfers: estimates ranged from 86-214 euros per capita for total expenditures (average 132), and 90-176 euros per capita for capital expenditures (average 129). This increase in expenditures is mostly financed through an increase in capital transfers (64-171 euros per capita depending on the specification, average 116), and a slight increase in loans (25-65 euros per capita, average 39). However, no significant general effect is found for current expenditures and tax revenues. Overall, the estimates seem to be lower than those found in the RDD analysis, which suggests that the latter were likely to be biased upward. Furthermore, the PBC seems to be greater for smaller bandwidths (even though they are less significant, because of smaller sample sizes). As we show in the next section, this is compatible with the idea that higher levels of political competition trigger strategic behaviors from incumbent mayors seeking re-election. Finally, for mayors who are term limited, we do not find any significant effect for any of the variables considered.

\footnotetext{
${ }^{28}$ In a Web Appendix, we report the T-tests for all the other covariates and all the bandwidths.
} 
Table 9: Reduction of bias in propensity score matching for different bandwidths

\begin{tabular}{|c|c|c|c|c|c|c|c|c|c|}
\hline Bandwidth & $\begin{array}{l}\text { Unmatched } \\
\text { Matched }\end{array}$ & Dynastic & $\begin{array}{l}\text { Experience } \\
\text { Non-dynastic }\end{array}$ & T-Stat & Dynastic & $\begin{array}{c}\text { Age } \\
\text { Non-dynastic }\end{array}$ & T-Stat & Smallest $p$-value in sample & Number obs. \\
\hline \multirow{2}{*}{$4 \%$} & $\mathrm{U}$ & 4.71 & 11.07 & 0.00 & 45.68 & 49.86 & 0.00 & 0.00 & 286 \\
\hline & $\mathrm{M}$ & 4.71 & 4.60 & 0.72 & 45.68 & 44.96 & 0.52 & 0.09 & 286 \\
\hline \multirow{2}{*}{$8 \%$} & $\mathrm{U}$ & 4.79 & 11.11 & 0.00 & 46.43 & 49.41 & 0.00 & 0.00 & 602 \\
\hline & M & 4.79 & 4.64 & 0.37 & 46.43 & 46.97 & 0.47 & 0.11 & 602 \\
\hline \multirow{2}{*}{$12 \%$} & $\mathrm{U}$ & 5.00 & 10.92 & 0.00 & 46.59 & 49.21 & 0.00 & 0.00 & 863 \\
\hline & M & 5.00 & 4.75 & 0.14 & 46.59 & 45.26 & 0.04 & 0.01 & 863 \\
\hline \multirow{2}{*}{$16 \%$} & $\mathrm{U}$ & 5.07 & 10.96 & 0.00 & 46.33 & 49.01 & 0.00 & 0.00 & 1090 \\
\hline & $\mathrm{M}$ & 5.08 & 5.06 & 0.88 & 46.37 & 45.96 & 0.49 & 0.12 & 1090 \\
\hline \multirow{2}{*}{$20 \%$} & $\mathrm{U}$ & 5.07 & 10.62 & 0.00 & 46.26 & 48.78 & 0.00 & 0.00 & 1294 \\
\hline & $\mathrm{M}$ & 5.08 & 4.89 & 0.10 & 46.29 & 46.30 & 0.98 & 0.01 & 1294 \\
\hline \multirow{2}{*}{$24 \%$} & $\mathrm{U}$ & 5.03 & 10.57 & 0.00 & 46.08 & 48.66 & 0.00 & 0.00 & 1466 \\
\hline & $\mathrm{M}$ & 5.03 & 5.04 & 0.91 & 46.08 & 45.31 & 0.14 & 0.14 & 1466 \\
\hline \multirow{2}{*}{$28 \%$} & $\mathrm{U}$ & 5.13 & 10.53 & 0.00 & 45.85 & 48.65 & 0.00 & 0.00 & 1572 \\
\hline & $\mathrm{M}$ & 5.13 & 5.22 & 0.35 & 45.85 & 44.95 & 0.06 & 0.05 & 1572 \\
\hline \multirow{2}{*}{$32 \%$} & $\mathrm{U}$ & 5.19 & 10.69 & 0.00 & 45.94 & 48.70 & 0.00 & 0.00 & 1682 \\
\hline & $\mathrm{M}$ & 5.19 & 5.07 & 0.23 & 45.94 & 45.70 & 0.62 & 0.23 & 1682 \\
\hline \multirow{2}{*}{$36 \%$} & $\mathrm{U}$ & 5.19 & 10.73 & 0.00 & 46.01 & 48.87 & 0.00 & 0.00 & 1771 \\
\hline & M & 5.19 & 5.04 & 0.15 & 46.01 & 46.06 & 0.92 & 0.04 & 1771 \\
\hline \multirow{2}{*}{$40 \%$} & $\mathrm{U}$ & 5.23 & 10.69 & 0.00 & 45.98 & 48.90 & 0.00 & 0.00 & 1836 \\
\hline & $\mathrm{M}$ & 5.23 & 5.28 & 0.64 & 45.98 & 45.46 & 0.23 & 0.11 & 1836 \\
\hline
\end{tabular}

This table reports the average of the considered variables among dynastic and non-dynastic elected mayors, in unmatched and matched samples, as well as the p-values of tests of differences between means across dynastic and non-dynastic individuals. 


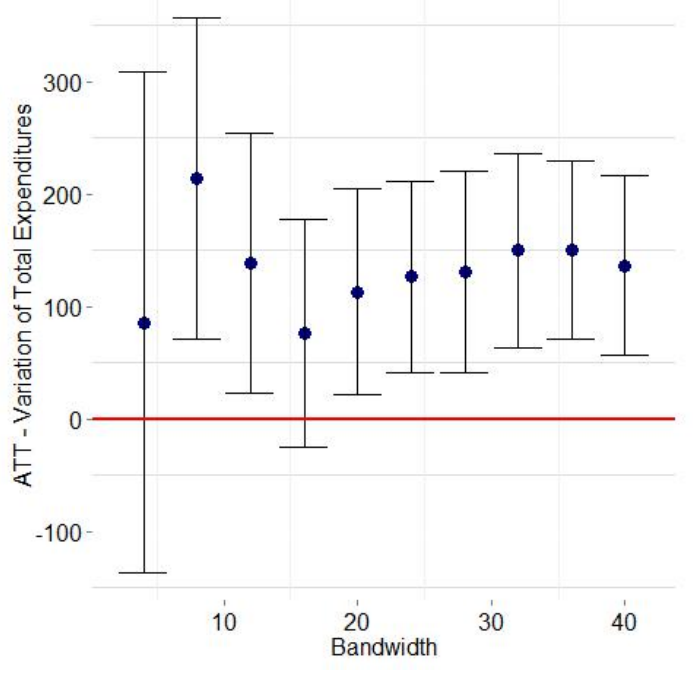

(a) Total

w

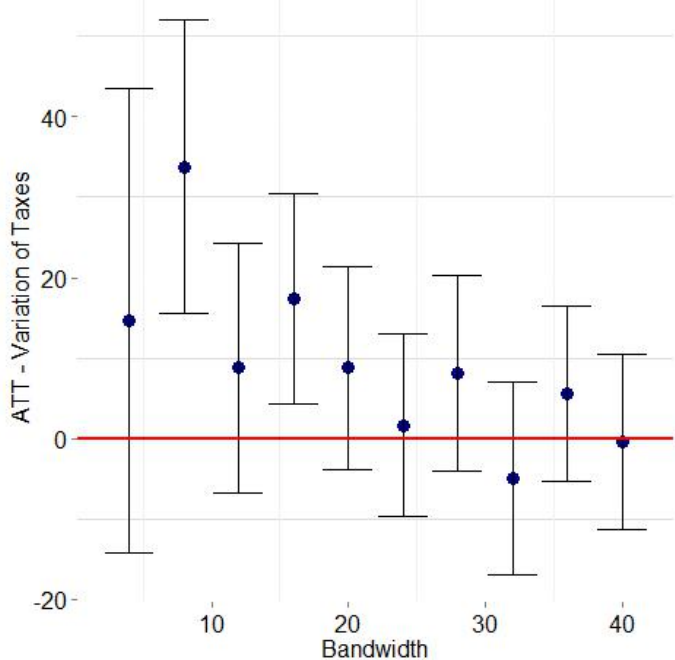

(d) Taxes

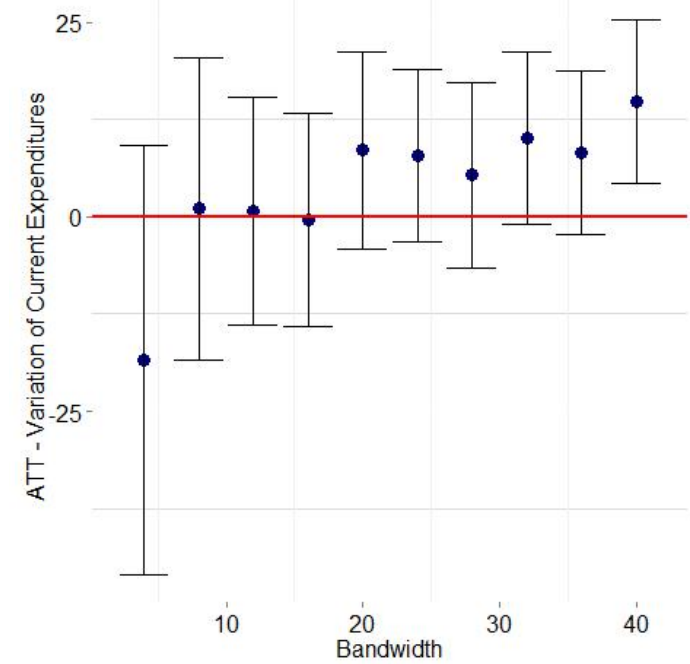

(b) Current

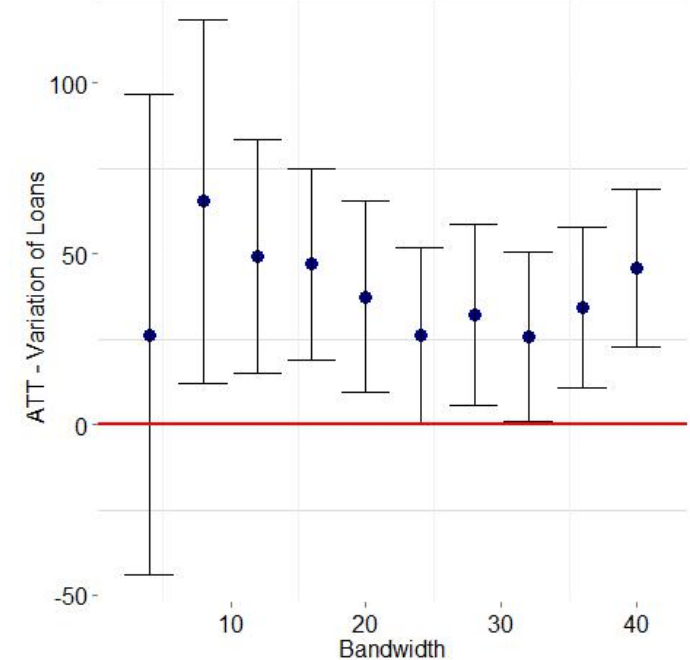

(e) Loans

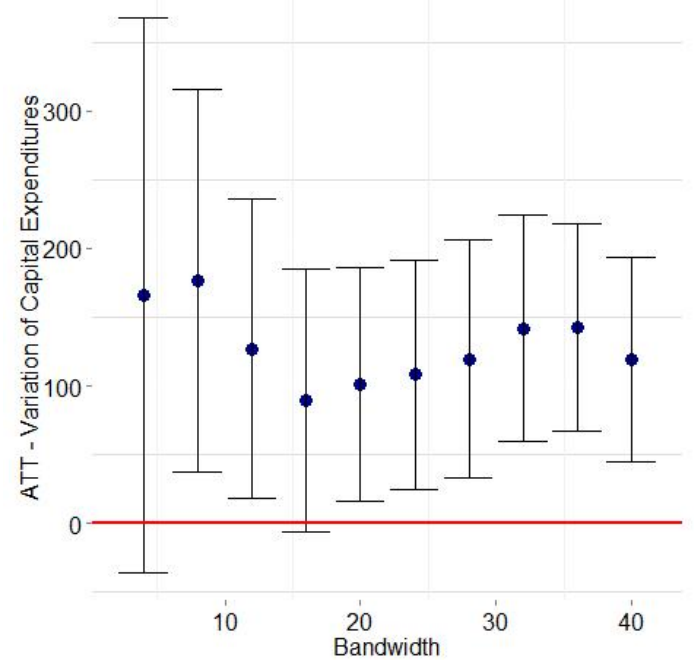

(c) Capital

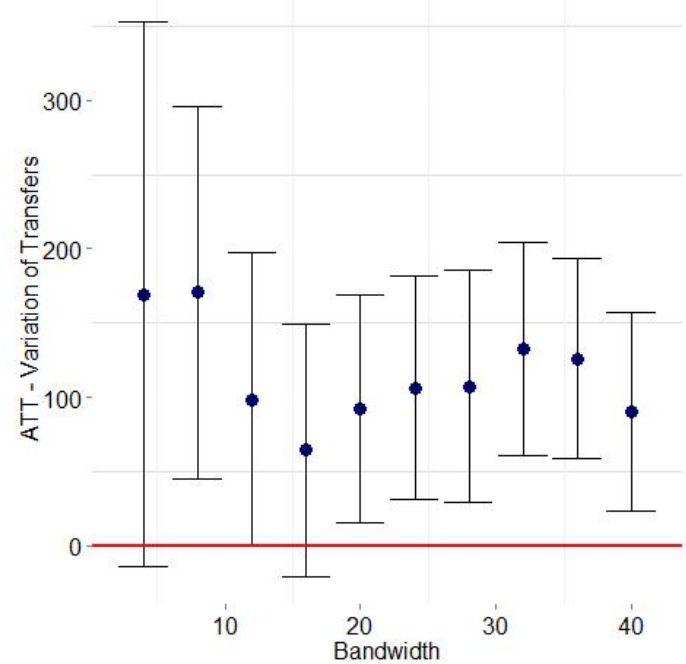

(f) Transfers

Figure 10: Matching estimates (ATT) - Non-term-limited mayors 


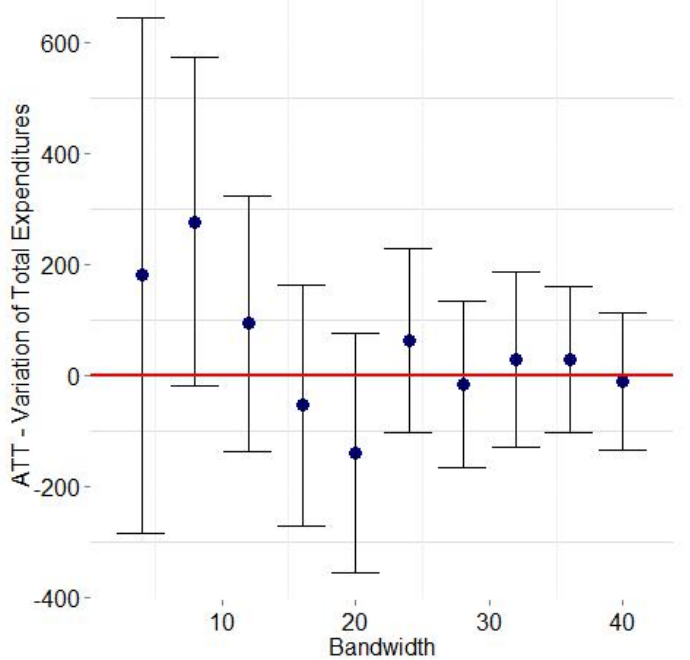

(a) Total

v

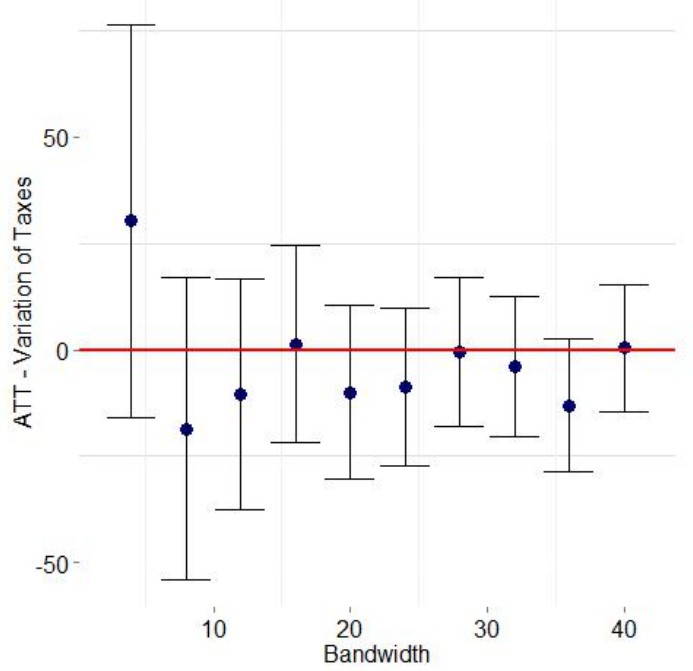

(d) Taxes

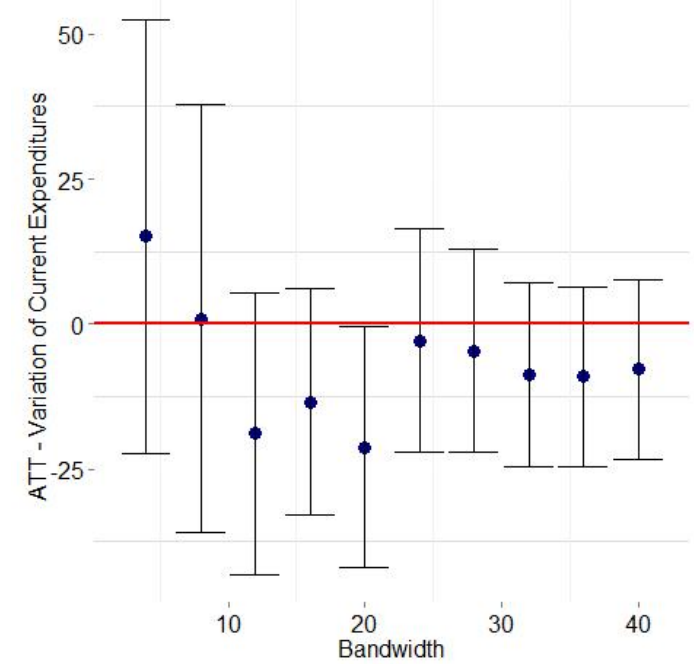

(b) Current

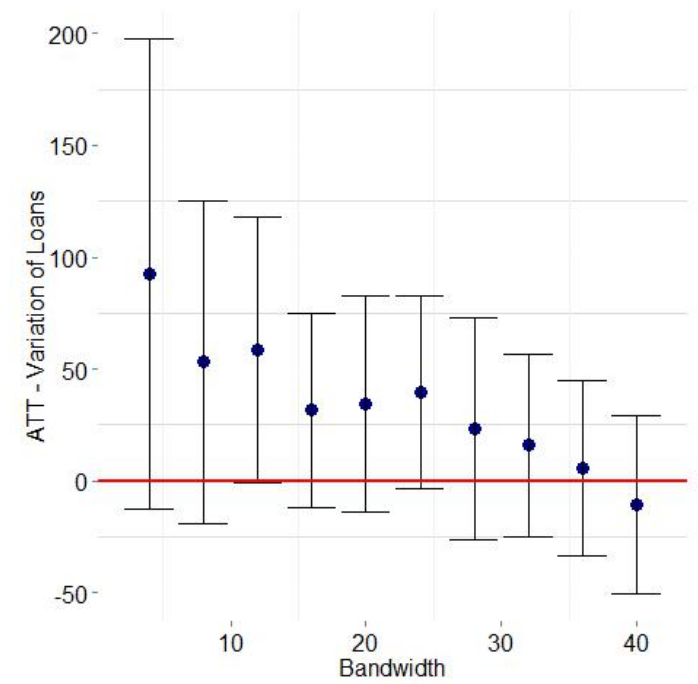

(e) Loans

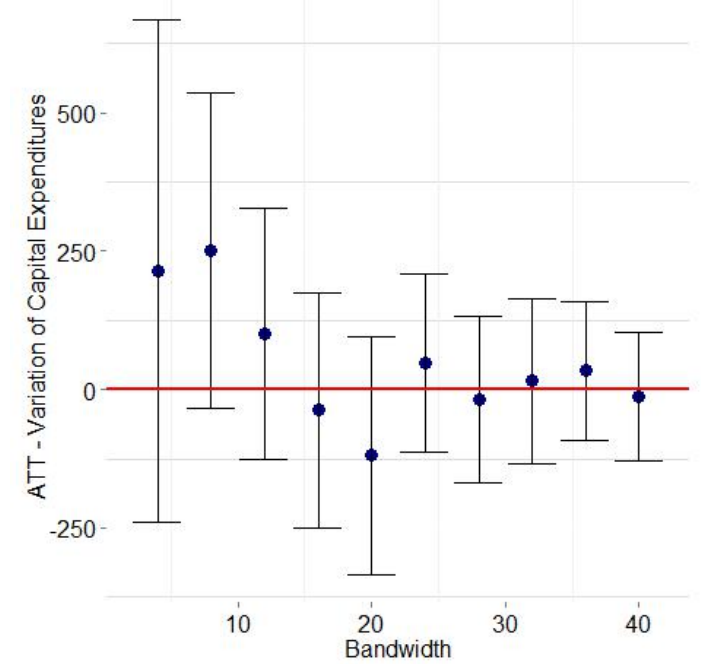

(c) Capital

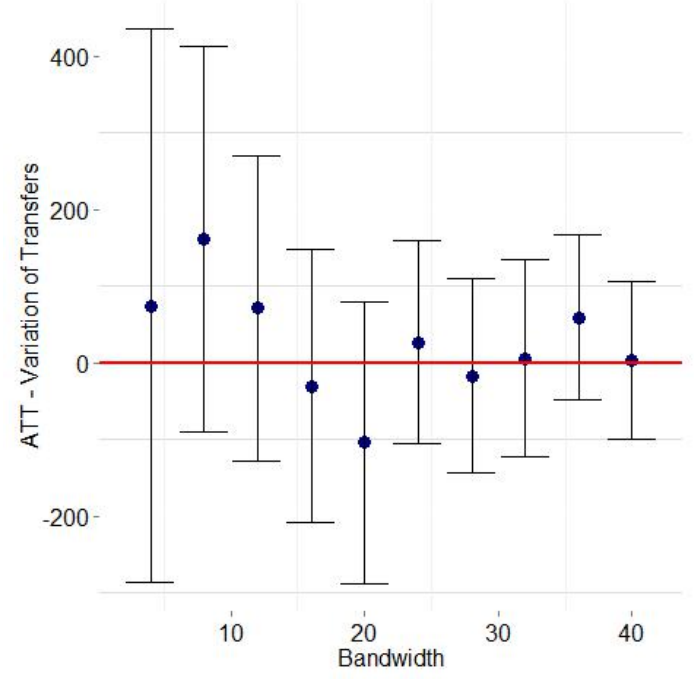

(f) Transfers

Figure 11: Matching estimates (ATT) - Term-limited mayors 


\section{Channels}

Dynastic mayors spend relatively more and receive more transfers from upper layers of government during their last year in office than their non-dynastic counterparts. Importantly, such a finding is likely to be explained by a more strategic behavior from dynastic mayors, without which we would be unlikely to observe any variation in expenditures or revenues across the term. The fact that on average, non-dynastic mayors also run PBCs suggests that these decisions are based on strategic motives (and that dynastic mayors, running higher PBCs, are therefore more strategic than non-dynastic mayors). As argued previously, this strategic behavior is likely to be explained by two main hypotheses: dynastic mayors might have more incentives to run higher PBCs (because of higher gains from politics), and/or a higher ability (or a lower cost) of enforcing them (due to the political experience accrued by their predecessors). However distinct, these two hypotheses are difficult to disentangle empirically, since the reasons why dynastic politicians are better at holding on to power might be the same as the ones helping them extract more gains from the political process. Yet, there is considerable empirical evidence that both mechanisms are at play. ${ }^{29}$

\subsection{Re-election incentives and electoral competitiveness}

The higher PBCs of dynastic mayors is visible only in their first term - when they are eligible for re-election. Provided that PBCs are used as a tool to help mayors get re-elected, such a finding can be interpreted in at least two different ways. First of all, for a given level of ability to signal their competence, dynastic mayors might have more to gain from remaining in office , and thus further increase spending via capital transfers (at the cost of a small increase in tax revenues, and a slightly higher debt burden in the future). Such a hypothesis is reinforced by the fact that dynastic mayors seem to be more likely to run for a second term (we develop this point in a Web Appendix). However, another way of analyzing this fact would be to consider that the amount of secured transfers indicates the competence of the mayor (as do Godefroy and Henry (2016) in their analysis of turnout and fiscal policy). In this case, to obtain a given gain from remaining in

\footnotetext{
${ }^{29}$ Note that the following tests are all based on fixed-effect estimations focusing on capital expenditures (the results are similar for total expenditures). Indeed, similar results hold when using the matching RDD estimation shown in Section 4.2.3. These results are available in the Web Appendix.
} 
Table 10: Liberal occupations and level of education

\begin{tabular}{|c|c|c|c|c|c|c|}
\hline \multirow[b]{2}{*}{ Capital expenditures } & \multicolumn{2}{|c|}{ Young and unexperienced } & \multicolumn{2}{|c|}{ Liberal occupation } & \multicolumn{2}{|c|}{ Highly educated } \\
\hline & Yes & No & Yes & No & Yes & No \\
\hline Dynasty & $\begin{array}{c}-55.343 \\
(1.02)\end{array}$ & $\begin{array}{l}15.892 \\
(0.49)\end{array}$ & $\begin{array}{c}-140.750 \\
(1.87)^{*}\end{array}$ & $\begin{array}{l}-1.956 \\
(0.09)\end{array}$ & $\begin{array}{l}40.584 \\
(1.15)\end{array}$ & $\begin{array}{l}7.194 \\
(0.23)\end{array}$ \\
\hline LY & $\begin{array}{l}43.769 \\
(2.06)^{* * *}\end{array}$ & $\begin{array}{c}38.048 \\
(2.95)^{* * *}\end{array}$ & $\begin{array}{c}-22.092 \\
(0.76)\end{array}$ & $\begin{array}{c}45.818 \\
(3.97)^{* * *}\end{array}$ & $\begin{array}{l}38.403 \\
(2.78)^{* * *}\end{array}$ & $\begin{array}{l}39.111 \\
(2.48)^{* * *}\end{array}$ \\
\hline TL & $\begin{array}{l}-43.289 \\
(2.04)^{* *}\end{array}$ & $\begin{array}{l}9.439 \\
(0.69)\end{array}$ & $\begin{array}{c}-53.605 \\
(1.34)\end{array}$ & $\begin{array}{c}-5.688 \\
(0.52)\end{array}$ & $\begin{array}{c}-20.045 \\
(1.25)\end{array}$ & $\begin{array}{l}3.099 \\
(0.20)\end{array}$ \\
\hline Dynasty ${ }^{*} \mathrm{LY}$ & $\begin{array}{l}91.031 \\
(2.80)^{* * *}\end{array}$ & $\begin{array}{c}44.672 \\
(1.56)\end{array}$ & $\begin{array}{l}162.896 \\
(2.54)^{* *}\end{array}$ & $\begin{array}{l}56.741 \\
(2.48)^{* *}\end{array}$ & $\begin{array}{l}57.407 \\
(1.83)^{*}\end{array}$ & $\begin{array}{l}75.325 \\
(2.53)^{* *}\end{array}$ \\
\hline $\mathrm{LY}{ }^{*} \mathrm{TL}$ & $\begin{array}{c}23.255 \\
(0.80)\end{array}$ & $\begin{array}{c}-12.945 \\
(0.76)\end{array}$ & $\begin{array}{c}21.312 \\
(0.55)\end{array}$ & $\begin{array}{c}-11.077 \\
(0.70)\end{array}$ & $\begin{array}{c}-19.454 \\
(0.93)\end{array}$ & $\begin{array}{l}0.805 \\
(0.04)\end{array}$ \\
\hline Dynasty*TL & $\begin{array}{l}90.088 \\
(1.76)^{*}\end{array}$ & $\begin{array}{l}0.619 \\
(0.02)\end{array}$ & $\begin{array}{c}106.904 \\
(1.19)\end{array}$ & $\begin{array}{l}8.899 \\
(0.34)\end{array}$ & $\begin{array}{c}-14.312 \\
(0.36)\end{array}$ & $\begin{array}{c}-0.092 \\
(0.00)\end{array}$ \\
\hline Dynasty* ${ }^{*} Y^{*} \mathrm{TL}$ & $\begin{array}{l}-89.261 \\
(1.54)\end{array}$ & $\begin{array}{c}-44.437 \\
(0.96)\end{array}$ & $\begin{array}{c}-133.584 \\
(1.03)\end{array}$ & $\begin{array}{c}-47.309 \\
(1.29)\end{array}$ & $\begin{array}{c}-46.550 \\
(0.82)\end{array}$ & $\begin{array}{c}-64.182 \\
(1.40)\end{array}$ \\
\hline $\begin{array}{l}R^{2} \\
N\end{array}$ & $\begin{array}{c}0.02 \\
14,634\end{array}$ & $\begin{array}{c}0.01 \\
31,274\end{array}$ & $\begin{array}{c}0.02 \\
4,510\end{array}$ & $\begin{array}{c}0.02 \\
41,398\end{array}$ & $\begin{array}{c}0.02 \\
18,674\end{array}$ & $\begin{array}{c}0.02 \\
27,234\end{array}$ \\
\hline $\begin{array}{l}\text { The table presents estimate } \\
\text { (winsorized at the } 1 \% \text { lev } \\
\text { those who have completed } \\
\text { that indicates (1) whether } \\
\text { election. The sample is co } \\
\text { of election are excluded fr } \\
\text { size and the mayor's sex, } \\
\text { T-Statistic in parentheses. } \\
{ }^{*} p<0.1 ; * * 0<0.05 \text {; }{ }^{* * *} p\end{array}$ & $\begin{array}{l}\text { mayor is d } \\
\text { rised of all } \\
\text { the estima } \\
\text { experienc }\end{array}$ & $\begin{array}{l}\text { dy (i.e., a univer } \\
\text { ) whether the } \mathrm{m} \\
\text { which two full } \\
\text { specifications } \mathrm{cc} \\
\text { of education and }\end{array}$ & $\begin{array}{l}\text { is term } \\
\text { in terms } \\
\text { for city }\end{array}$ & $\begin{array}{l}\mathrm{d} \text { and (3) } \\
\text { observed } \\
\text { year fixed }\end{array}$ & $\begin{array}{l}\text { er it is th } \\
\text { een } 1999\end{array}$ & $\begin{array}{l}\text { lent variable } \\
\text { mayors are } \\
\text { re dummies } \\
\text { ar before an } \\
\text { 2012. Years } \\
\text { population } \\
\text { e city level }\end{array}$ \\
\hline
\end{tabular}

office, dynastic mayors might be better at producing a positive signal of their ability, by securing more transfers from upper layers of government, which are then spent in additional visible expenditures (which are thus financed at a low cost to the taxpayers).

The key role of the electoral context is further substantiated by the results of the matching estimation, which suggest that closely elected dynastic mayors are more likely to have larger PBCs. ${ }^{30}$ Note that this result is not incompatible with the fact that dynastic mayors are more likely to be re-elected: indeed, because of electoral uncertainty, mayors might be pushed to enforce policies that favor their re-election even when they are relatively more likely to win than other candidates. Consistent with this hypothesis, our results indicate that PBCs are higher when electoral

\footnotetext{
${ }^{30}$ Note that such a finding cannot be attributed to potential biases due to the small sample size, as we find similar results in the fixed-effects specification: the difference in PBCs between dynastic and non-dynastic mayors is typically higher among mayors who won the election by a small margin.
} 
uncertainty is greater, suggesting that the mechanisms presented above are likely to play an even more important role when the power of the mayor is challenged. ${ }^{31}$

\subsection{Career incentives, occupations and level of education}

A broad set of explanations might be linked to the political and professional experience of the dynastic politicians, which might affect both their abilities and the incentives they face. In Table 10, we estimate the differences in PBCs between dynastic and non-dynastic mayors on different subsamples. We find that dynastic mayors are much more prone to run PBCs than their counterparts when they are both young and inexperienced (more specifically, when they are both below the median age and median experience of all mayors at the beginning of their term). Such a finding is especially compatible with a career concern motive (as proposed by Alesina et al. (2015) about young mayors, and as suggested by our results in Section 3): young and dynastic mayors expect to have a longer career in politics, and therefore might have greater incentives to remain in office. Furthermore, given that experience is a strong predictor of re-election, their lack of experience might call for stronger PBCs.

But career concerns might not only apply to younger and less-experienced dynastic mayors. Indeed, we have seen that on average, dynastic mayors are slightly less educated than nondynastic mayors (Table 2). Therefore, one could expect dynastic mayors to have more incentives to stay longer in office as, all else equal, they are likely to earn less on the labor market. However, this hypothesis does not seem to be confirmed by Columns 5 and 6 of Table 10, which separately analyze less-educated and highly educated mayors (i.e., with/without a university degree). Less-educated dynastic mayors have slightly higher PBCs, but such differences are not statistically significant.

Finally, the professional experience of dynastic mayors is also likely to play a role. Our findings show that dynastic mayors with liberal occupations also have higher PBCs: when we restrict our sample to mayors who are lawyers, doctors or notaries (i.e., professions based on local networks and reputation), the relative $\mathrm{PBC}$ s of dynastic mayors are much higher than for mayors with

\footnotetext{
${ }^{31} \mathrm{~A}$ further question is whether higher PBCs actually help win elections. We address this point in the Web Appendix, where we show that PBCs do not seem to affect electoral performance (for similar findings, see Brender and Drazen (2008).
} 
Table 11: PBCs of capital expenditures for different city sizes and birthplaces

\begin{tabular}{lccccccc}
\hline \multirow{2}{*}{ Capital Expenditures } & \multicolumn{3}{c}{ Population } & \multicolumn{3}{c}{ Born in city } & \multicolumn{3}{c}{ Born in province } \\
& $<1,500$ & $\in] 1,500,15,000]$ & $>15,000$ & Yes & No & Yes & No \\
\hline Dynasty & 41.511 & -8.539 & -89.038 & -14.315 & -12.749 & -4.428 & -64.047 \\
& $(1.04)$ & $(0.48)$ & $(2.85)^{* * *}$ & $(0.35)$ & $(0.39)$ & $(0.20)$ & $(0.76)$ \\
LY & 51.654 & 32.188 & 41.166 & 38.059 & 35.933 & 30.696 & 98.133 \\
& $(2.18)^{* *}$ & $(3.21)^{* * *}$ & $(2.90)^{* * *}$ & $(2.46)^{* *}$ & $(2.41)^{* *}$ & $(2.68)^{* * *}$ & $(3.40)^{* * *}$ \\
TL & -4.520 & -16.162 & -7.636 & -11.763 & -21.700 & -5.744 & -47.467 \\
& $(0.19)$ & $(1.67)^{*}$ & $(0.64)$ & $(0.68)$ & $(1.51)$ & $(0.51)$ & $(1.73)^{*}$ \\
Dynasty*LY & 84.168 & 38.830 & 16.835 & 46.384 & 92.401 & 76.063 & 8.859 \\
& $(2.15)^{* *}$ & $(1.87)^{*}$ & $(0.54)$ & $(1.59)$ & $(2.87)^{* * *}$ & $(3.32)^{* * *}$ & $(0.15)$ \\
LY*TL & -33.719 & 11.174 & -17.534 & -1.448 & -12.382 & 1.364 & -54.177 \\
& $(1.06)$ & $(0.82)$ & $(0.95)$ & $(0.07)$ & $(0.61)$ & $(0.08)$ & $(1.60)$ \\
Dynasty*TL & 19.865 & 4.744 & 59.768 & 54.004 & -7.263 & 20.980 & 4.356 \\
& $(0.45)$ & $(0.20)$ & $(1.46)$ & $(1.50)$ & $(0.18)$ & $(0.79)$ & $(0.04)$ \\
Dynasty*${ }^{*} Y^{*} \mathrm{TL}$ & -29.321 & -77.795 & -65.057 & -29.041 & -92.171 & -65.386 & -42.123 \\
& $(0.46)$ & $(2.24)^{* *}$ & $(1.53)$ & $(0.58)$ & $(1.85)^{*}$ & $(1.74)^{*}$ & $(0.38)$ \\
$R^{2}$ & 0.02 & 0.03 & 0.12 & 0.02 & 0.02 & 0.02 & 0.02 \\
$N$ & 19,406 & 23,799 & 2,703 & 22,918 & 22,990 & 39,624 & 6,284 \\
\hline
\end{tabular}

The table presents estimates from fixed-effects panel regressions, using capital expenditures per capita as a dependent variable (winsorized at the $1 \%$ level). Regressions are run on different subsamples of cities, defined according to their population in 2001. The main explanatory variables are dummies indicating (1) whether the mayor is dynastic, (2) whether the mayor is term limited and (3) whether it is the year before an election. Each subsample is comprised of cities for which two full 5-year terms were observed between 1999 and 2012. Election years are excluded from the estimation. All specifications control for city and year fixed effects, as well as population size and the mayor's sex, age, experience, years of education and birthplace. Standard errors are clustered at the city level. T-Statistic in parentheses.

${ }^{*} p<0.1 ;{ }^{* *} p<0.05 ;{ }^{* * *} p<0.01$

other occupations. This finding is in line with the idea that local elites hold power through reputation and local networks that can be transmitted over generations.

\subsection{City size and birthplace}

An important finding is that the relative PBCs of dynastic mayors vary by city size. As Table 11 shows, dynastic mayors are relatively much more likely to run PBCs in small cities. An effect is still detected for medium-size cities, but no effect is noticeable when the sample is restricted to big cities. ${ }^{32}$ Two alternative hypotheses could explain these differences. First, assumed dynastic individuals are more likely to be identified in smaller cities. ${ }^{33}$ Second, the incentive and ability to run PBCs are likely to depend on the size of the city. Our results suggest that the advantages

\footnotetext{
${ }^{32}$ Even though such restrictions impose a dramatic drop in the sample size, it is unlikely that this absence of a result is only due to a loss of power. Indeed, PBCs do not disappear when we restrict our analysis to bigger cities: in fact, their magnitudes are similar. The main difference is that dynastic politicians do not have higher PBCs than other politicians in big cities.

${ }^{33}$ This may be because surname diversity is higher in bigger cities; therefore, because municipal council sizes do not increase linearly with the size of the city, we can expect to identify more assumed dynastic individuals in smaller cities. Furthermore, greater family diversity in bigger cities makes it more likely that we identify only homonyms
} 
and incentives inherent to dynasties are higher in smaller municipalities: this might be due to stronger family ties and more salient reputational effects.

Another way of testing whether mayors from more powerful families have greater incentives or power to remain in office is to consider the mayor's birthplace, since if he was the born in the city, his family might have stronger local power. We have shown above that dynastic mayors are more likely to be born in the city in which they hold office. Yet, as shown in Table 11, dynastic mayors who were born in the city they run have a lower relative $\mathrm{PBC}$ than mayors who were not. Such a result does not invalidate the hypothesis that dynastic mayors with stronger local influence have more power and more incentives to remain in office for several reasons. First, this result might be explained by the fact that cities with doctors or hospitals with maternity wards are also bigger (where the PBCs of dynastic mayors are also lower). Second, as shown in Columns 6 and 7 of the table, we do not find any additional PBCs for dynastic mayors who were not born in the province of the city they run, while for mayors born in the province, the estimated additional PBC is even higher than in the baseline specification. Therefore, our baseline results are not driven by atypical cases of mayors having weak ties at the local level. Our interpretation is further substantiated by the fact that mayors who had two or more family members in office before them have higher PBCs than mayors who are only the second individual of the dynasty in office. ${ }^{34}$ Furthermore, if we define mayors as dynastic only if they and their assumed predecessor were born in the city or the province they run (84\% of all dynastic mayors), the effect of dynasty is even stronger than in the baseline specification. ${ }^{35}$

rather than individuals in the same family. If we more accurately identify dynasties in smaller municipalities, it is likely that we estimate stronger effects in the latter.

${ }^{34}$ This estimation strategy is, however, imperfect in this setup as we might give more weight to individuals with common surnames, or to homonyms with no family ties. These results are available upon request.

${ }^{35}$ The results of these estimations are presented in a Web Appendix. 
Table 12: Mafia infiltration, southern regions and first generations

\begin{tabular}{|c|c|c|c|c|c|c|c|}
\hline Capital expenditures & Non-south & South & Non-Mafia region & Mafia region & Capital expenditures & All mayors & Dynastic or First gen \\
\hline Dynasty & $\begin{array}{c}-25.757 \\
(1.19)\end{array}$ & $\begin{array}{c}39.015 \\
(0.91)\end{array}$ & $\begin{array}{c}-10.775 \\
(0.51)\end{array}$ & $\begin{array}{c}14.331 \\
(0.28)\end{array}$ & First Generation & $\begin{array}{c}14.074 \\
(0.74)\end{array}$ & $\begin{array}{c}22.972 \\
(0.70)\end{array}$ \\
\hline LY & $\begin{array}{l}31.266 \\
(2.55)^{* *}\end{array}$ & $\begin{array}{c}33.088 \\
(1.41)\end{array}$ & $\begin{array}{c}35.411 \\
(3.09)^{* * *}\end{array}$ & $\begin{array}{l}8.079 \\
(0.28)\end{array}$ & LY & $\begin{array}{c}63.679 \\
(5.94)^{* * *}\end{array}$ & $\begin{array}{c}102.487 \\
(4.77)^{* * *}\end{array}$ \\
\hline TL & $\begin{array}{l}0.395 \\
(0.04)\end{array}$ & $\begin{array}{l}-53.769 \\
(1.97)^{* *}\end{array}$ & $\begin{array}{r}-1.851 \\
(0.18)\end{array}$ & $\begin{array}{c}-43.332 \\
(1.24)\end{array}$ & TL & $\begin{array}{l}4.356 \\
(0.43)\end{array}$ & $\begin{array}{r}-2.667 \\
(0.11)\end{array}$ \\
\hline Dynasty*LY & $\begin{array}{c}72.529 \\
(2.95)^{* * *}\end{array}$ & $\begin{array}{c}54.071 \\
(1.26)\end{array}$ & $\begin{array}{c}67.159 \\
(2.86)^{* * *}\end{array}$ & $\begin{array}{c}78.829 \\
(1.46)\end{array}$ & First Geeration*LY & $\begin{array}{c}-30.620 \\
(1.43)\end{array}$ & $\begin{array}{c}-78.742 \\
(2.87)^{* * *}\end{array}$ \\
\hline $\mathrm{LY} * \mathrm{TL}$ & $\begin{array}{c}-13.274 \\
(0.87)\end{array}$ & $\begin{array}{c}32.958 \\
(0.85)\end{array}$ & $\begin{array}{c}-14.140 \\
(0.93)\end{array}$ & $\begin{array}{c}27.011 \\
(0.56)\end{array}$ & $\mathrm{LY}^{*} \mathrm{TL}$ & $\begin{array}{l}-35.715 \\
(2.38)^{* *}\end{array}$ & $\begin{array}{l}-69.005 \\
(2.11)^{* *}\end{array}$ \\
\hline Dynasty ${ }^{*} \mathrm{TL}$ & $\begin{array}{c}23.847 \\
(0.88)\end{array}$ & $\begin{array}{c}33.215 \\
(0.65)\end{array}$ & $\begin{array}{c}22.674 \\
(0.87)\end{array}$ & $\begin{array}{l}7.163 \\
(0.11)\end{array}$ & First Generation*TL & $\begin{array}{c}-32.544 \\
(1.33)\end{array}$ & $\begin{array}{c}-63.414 \\
(1.80)^{*}\end{array}$ \\
\hline Dynasty*LY*TL & $\begin{array}{c}-41.396 \\
(1.08)\end{array}$ & $\begin{array}{c}-112.426 \\
(1.44)\end{array}$ & $\begin{array}{c}-41.730 \\
(1.12)\end{array}$ & $\begin{array}{c}-127.194 \\
(1.27)\end{array}$ & First Generation*LY*TL & $\begin{array}{l}60.383 \\
(1.86)^{*}\end{array}$ & $\begin{array}{c}86.478 \\
(1.98)^{* *}\end{array}$ \\
\hline $\begin{array}{l}R^{2} \\
N\end{array}$ & $\begin{array}{c}0.02 \\
34,865\end{array}$ & $\begin{array}{c}0.03 \\
11,043\end{array}$ & $\begin{array}{c}0.02 \\
39,071\end{array}$ & $\begin{array}{c}0.02 \\
6,837\end{array}$ & $\begin{array}{l}R^{2} \\
N\end{array}$ & $\begin{array}{c}0.02 \\
45,908\end{array}$ & $\begin{array}{c}0.02 \\
20,334\end{array}$ \\
\hline
\end{tabular}

The table presents estimates from fixed-effects panel regressions, using capital expenditures per capita as a dependent variable (winsorized at the 1\% level). Southern regions are Abruzzo, Basilicata, Calabria, Campania, Molise, Puglia, Sardegna and Sicilia. Mafia regions include Calabria, Campania and Sicilia. In the first four columns, the main explanatory variables are dummies indicating (1) whether the mayor is dynastic, (2) whether the mayor is term limited and (3) whether it is the year before an election.In the last two columns, the main explanatory variables include dummies indicating (1) whether the mayor is the first in his family to be in the municipal council, (2) whether the mayor is term limited and (3) whether it is the year before an election. In Column 5, the estimation is run on all types of mayors, while in Column 6it is run on mayors who are part of a political family (either as the first generation or as a dynasty). The sample is comprised of all cities for which two full 5-year terms were observed between 1999 and 2012. Election years are excluded from the estimation. All specifications control for city and year fixed effects, as well as population size and the mayor's sex, age, experience, years of education and birthplace. Standard errors are clustered at the city level. T-Statistic in parentheses.

${ }^{*} p<0.1 ;{ }^{* *} p<0.05 ; * * * p<0.01$ 


\subsection{Founders of dynasties}

Overall, our framework allows us to explore the extent to which local budgets can be used as a tool not only for re-election, but also for the intergenerational transmission of power. More specifically, we can test whether the founders of dynasties and dynastic politicians exhibit the same behavior in office. If the gains from being in office and the political skills of dynastic individuals - and therefore their incentives to remain in office - are higher precisely because of the legacy of their predecessors, we expect to find no significant difference between the "founders" of political dynasties and other non-dynastic mayors. The second panel of Table 12 confirms this prediction. The first column uses the full sample of observations, and tests whether firstgeneration-dynasty mayors have higher capital expenditures than non-dynastic mayors during the last year before an election: the results suggest that non-term-limited mayors do not. However, we find a weakly significant increase for term-limited ones. While this is not compatible with individual electoral incentives, it could be in line with family electoral incentives, whereby the founders of a dynasty have a higher PBC in their second term than in their first term, since their relatives might enter the political arena and benefit from it. ${ }^{36}$ The second column tests whether there is a difference in PBCs between dynastic mayors and founders of dynasties: we estimate the same equation as in Column 1, but keeping only these two types of mayors. The results are in line with our prediction, as first generations of dynasties are found to spend much less than dynastic mayors during the last year of their first term (about 78 euros per capita).

\subsection{Geographic variation and social capital}

Another explanation for the different policies implemented by dynastic mayors might be the economic and social environment in which they live. Therefore, one could expect that dynastic mayors have less opportunistic policies in the north than in the south (which, according to the seminal case study of Banfield (1967), is characterized by a form of "amoral familism") and in regions with a high mafia prevalence (Campania, Calabria and Sicilia, see Daniele and Geys (2015) and literature therein). However, as emphasized in Table 12, this is not what we find: if

\footnotetext{
${ }^{36}$ However, we do not find that first generations who had a family member running for office immediately after them had a relatively higher PBC. Furthermore, comparing first generations to other non-dynastic mayors, we do not find significant differences in PBCs between them in the second term. Therefore, while this result suggests a potential channel to explain the intergenerational transmission of power highlighted in Figure $4 \mathrm{a}$, its causes and implications deserve careful analysis, which we reserve for future research.
} 
Table 13: Competence of dynastic mayors

\begin{tabular}{lcccc}
\hline & Average length of term & Ability rev. collection & Speed payment & Growth tax base \\
\hline Dynasty & -0.041 & -0.176 & 0.178 & 0.002 \\
& $(1.85)^{*}$ & $(0.50)$ & $(0.86)$ & $(0.83)$ \\
TL & 0.026 & 0.071 & 0.214 & -0.000 \\
& $(1.90)^{*}$ & $(0.39)$ & $(1.99)^{* *}$ & $(0.24)$ \\
Dynasty*TL & 0.084 & 0.043 & -0.444 & -0.002 \\
& $(2.96)^{* * *}$ & $(0.10)$ & $(1.86)^{*}$ & $(0.82)$ \\
$R^{2}$ & 0.77 & 0.13 & 0.03 & 0.46 \\
$N$ & 26,447 & 44,056 & 44,052 & 16,437 \\
\hline
\end{tabular}

The table presents estimates from fixed-effects panel regressions. Dependent variables are the mayors' average term length (measured in years), ability to collect revenue (measured as a ratio of collected revenue over expected revenue), speed of payment (measured as the share of due expenditures paid during the term) and the yearly growth rate of the private tax base (measured in percentage points). The main explanatory variables are dummies indicating (1) whether the mayor is dynastic and(2) whether the mayor is term limited. In Column 1, observations are aggregated at the term level, and include all observed terms between 1998 and 2012. Estimations of Columns 2, 3 and 4 are at the yearly level. Columns 2 and 3 include all cities for which two full terms were observed between 1999 and 2012, while Column 4 includes all cities for which at least one full term was observed between 2001 and 2011. Election years are excluded from the estimation. All specifications control for city and year fixed effects as well as population size, and for the mayor's sex, age, experience, years of education and birthplace. Standard errors are clustered at the city level. T-Statistic in parentheses. ${ }^{*} p<0.1 ;{ }^{* *} p<0.05 ;{ }^{* * *} p<0.01$

anything, dynastic mayors seem to be more opportunistic in central and northern regions, and while their PBCs are relatively higher in mafia regions, the estimated effect is not significant. ${ }^{37}$

\subsection{City performances}

Finally, one could also expect that if dynastic politicians benefit from the political experience of their predecessors, their city should show better performance during their term. We have seen that, on average, dynastic politicians do not seem to spend more than other mayors. However, this result hardly predicts differences in city performance. Table 13 directly tests whether dynastic mayors indeed perform better in office by analyzing their impact on several outcome variables indicating the quality of their governance:the length of their term (shorter terms indicate a higher probability of early termination, i.e., political instability), their ability to collect revenue and reimburse their debt ontime, and the growth of the private tax base over the term (a proxy for the city's GDP). ${ }^{38}$ Overall, we find no clear effects of political dynasty (in either the

\footnotetext{
${ }^{37}$ Another explanation could be linked to social capital. Indeed, as emphasized by Nannicini et al. (2013), clientelistic behaviors are less likely to be punished in low social capital areas. Yet we find that, in line with the heterogeneity analysis between northern and southern regions, dynastic mayors are not more opportunistic in low social capital areas (defined as cities with high unemployment and a low level of blood donations. Results available upon request).

${ }^{38}$ In Column 1 our period of observation is an entire electoral term instead of yearly observations.
} 
Table 14: Fixed effects: PBCs for mayors whose names are not among the 100 most common surnames in the province

\begin{tabular}{lcccccc}
\hline & Total exp & Current exp & Capital exp & Tax rev & Loans & Cap. transfers \\
\hline Dynasty & 12.656 & 4.648 & 5.310 & 3.966 & -1.683 & 5.411 \\
& $(0.41)$ & $(0.74)$ & $(0.21)$ & $(1.32)$ & $(0.21)$ & $(0.22)$ \\
LY & 43.763 & -0.991 & 33.169 & -8.270 & 9.285 & 18.123 \\
& $(3.10)^{* * *}$ & $(0.52)$ & $(2.61)^{* * *}$ & $(6.63)^{* * *}$ & $(2.25)^{* *}$ & $(1.57)$ \\
TL & -3.683 & 2.871 & -11.203 & -2.637 & -4.357 & 0.662 \\
& $(0.25)$ & $(0.89)$ & $(0.90)$ & $(1.66)^{*}$ & $(1.14)$ & $(0.06)$ \\
Dynasty*${ }^{*} Y$ & 106.305 & 7.739 & 105.337 & 7.809 & 28.945 & 81.511 \\
& $(3.47)^{* * *}$ & $(2.11)^{* *}$ & $(3.72)^{* * *}$ & $(3.15)^{* * *}$ & $(3.19)^{* * *}$ & $(3.13)^{* * *}$ \\
LY*TL & -10.068 & 2.256 & -7.443 & 7.048 & 5.232 & -15.032 \\
& $(0.53)$ & $(0.90)$ & $(0.43)$ & $(4.01)^{* * *}$ & $(0.96)$ & $(0.98)$ \\
Dynasty*TL & -3.235 & 7.960 & 3.130 & 2.079 & -8.431 & 1.456 \\
& $(0.09)$ & $(1.05)$ & $(0.10)$ & $(0.56)$ & $(0.79)$ & $(0.05)$ \\
Dynasty*${ }^{*} Y^{*} \mathrm{TL}$ & -46.642 & 0.138 & -62.954 & -1.809 & -30.946 & -50.339 \\
& $(0.93)$ & $(0.02)$ & $(1.38)$ & $(0.43)$ & $(2.20)^{* *}$ & $(1.22)$ \\
$R^{2}$ & 0.02 & 0.25 & 0.01 & 0.41 & 0.01 & 0.01 \\
$N$ & 33,085 & 33,085 & 33,085 & 33,094 & 33,092 & 33,092 \\
\hline
\end{tabular}

The table presents estimates from fixed-effects panel regressions, using categories of public expenditures and revenues as dependent variables (all are expressed in euros per capita, and winsorized at the $1 \%$ level). The main explanatory variables are dummies indicating (1) whether the mayor is dynastic, (2) whether the mayor is term limited and (3) whether it is the year before an election. The sample is comprised of all cities with a mayor who did not have a name among the 100 most common at the province level, and where two full 5-year terms were observed between 1999 and 2012. Election years are excluded from the estimation. All specifications control for city and year fixed effects as well as population size, and for the mayor's sex, age, experience, years of education and birthplace. Standard errors are clustered at the city level. T-Statistic in parentheses.

${ }^{*} p<0.1 ;{ }^{* *} p<0.05 ; * * * p<0.01$

first or second term) on these variables, showing that dynastic mayors are unlikely to be more (or less) competent.

\section{Robustness tests}

In this section, we present different robustness tests based on the alternative definitions of dynastic mayors presented above. We present the results of the fixed-effects specifications, while the results of the matching RDD are reported in the Web Appendix.

As shown in Table 14, the results are robust to excluding mayors who have one of the 100 most common surnames in the province (for a similar approach, see Geys (2016)). ${ }^{39}$ As argued above, dropping individuals with the 100 most common surnames at the province level amounts to excluding about $20 \%$ of the initial sample, while dropping those with the 500 most common

\footnotetext{
${ }^{39}$ Results excluding the 500 most common names in the province are presented in a Web Appendix.
} 
Table 15: Fixed effects: PBC for dynastic mayors with 10-year window

\begin{tabular}{lcccccc}
\hline & Total exp & Current exp & Capital exp & Tax rev & Loans & Cap. transfers \\
\hline Dynasty & 5.243 & -1.009 & 0.857 & 1.679 & 8.552 & -7.311 \\
& $(0.21)$ & $(0.19)$ & $(0.04)$ & $(0.71)$ & $(1.41)$ & $(0.38)$ \\
LY & 47.558 & -1.938 & 39.458 & -8.624 & 12.846 & 23.508 \\
& $(4.07)^{* * *}$ & $(1.14)$ & $(3.71)^{* * *}$ & $(8.03)^{* * *}$ & $(3.70)^{* * *}$ & $(2.47)^{* * *}$ \\
TL & -3.664 & 3.699 & -11.017 & -3.080 & -0.790 & -4.644 \\
& $(0.30)$ & $(1.33)$ & $(1.04)$ & $(2.26)^{* *}$ & $(0.24)$ & $(0.48)$ \\
Dynasty*LY & 69.137 & 9.356 & 64.782 & 7.827 & 19.728 & 52.286 \\
& $(3.01)^{* * *}$ & $(3.13)^{* * *}$ & $(3.04)^{* * *}$ & $(3.68)^{* * *}$ & $(2.88)^{* * *}$ & $(2.69)^{* * *}$ \\
LY*TL & -7.128 & 2.912 & -6.822 & 8.367 & -2.365 & -8.240 \\
& $(0.44)$ & $(1.26)$ & $(0.46)$ & $(5.52)^{* * *}$ & $(0.50)$ & $(0.64)$ \\
Dynasty*TL & 16.668 & 13.118 & 16.548 & 1.221 & -10.839 & 20.456 \\
& $(0.59)$ & $(2.07)^{* *}$ & $(0.69)$ & $(0.40)$ & $(1.30)$ & $(0.94)$ \\
Dynasty*${ }^{*} Y^{*} \mathrm{TL}$ & -40.614 & -2.359 & -53.467 & -4.908 & -19.205 & -55.347 \\
& $(1.05)$ & $(0.49)$ & $(1.52)$ & $(1.41)$ & $(1.77)^{*}$ & $(1.79)^{*}$ \\
$R^{2}$ & 0.02 & 0.24 & 0.02 & 0.42 & 0.01 & 0.01 \\
$N$ & 46,124 & 46,124 & 46,124 & 46,125 & 46,123 & 46,123 \\
\hline
\end{tabular}

The table presents estimates from fixed-effects panel regressions, using categories of public expenditures and revenues as dependent variables (all are expressed in euros per capita, and winsorized at the $1 \%$ level). The dummy variable indicating whether a mayor is dynastic is equal to 1 if an individual had a relative in the municipal council during the 10 years prior to his election to the municipal council. Other explanatory variables are dummies indicating (1) whether the mayor is term limited and (2) whether it is the year before an election. The sample is comprised of all cities for which two full 5-year terms were observed between 1999 and 2012. Election years are excluded from the estimation. All specifications control for city and year fixed effects as well as population size, and for the mayor's sex, age, experience, years of education and birthplace. Standard errors are clustered at the city level. T-Statistic in parentheses.

${ }^{*} p<0.1 ;{ }^{* *} p<0.05 ;{ }^{* * *} p<0.01$

surnames amounts to dropping about $50 \%$ of the sample. Yet we find that dynasty has robust, significant effects on PBCs in the first term, with much higher estimated coefficients than in the baseline specification (for example, while the estimated impact of dynasty on the increase in capital expenditures is about 68 euros per capita in the baseline specifications, it is 105 when we exclude the 100 most common surnames, and 125 when we exclude the 500 most common surnames). These results seem to confirm that our initial results were biased downwards because of homonymy.

A second robustness check tests whether the results hold when we define as dynastic only mayors who had a relative in office during the previous 10 years. This definition imposes a common constraint on all identified dynastic mayors, and overcomes the potential bias induced by the fact that dynastic mayors at the beginning of the period are structurally different from those identified at the end of the period. Table 15 shows that the results are similar in magnitude to the baseline specifications. 


\section{Conclusion}

In this paper, we provide several insights about the relevance of dynasties in the political arena. Our test is based on data from Italian municipalities in the period 1985-2012 (and on mayoral elections in the period 1998-2012). Our main contribution is a test of whether dynastic mayors perform differently than non-dynastic mayors. Such differences might be due to higher ability thanks to inherited political skills and/or higher gains from being in office. In line with such a hypothesis, we find that dynastic mayors spend more (on capital expenditure) - and receive more transfers - in the year before an election, but only when they are eligible to run for reelection. We provide several tests in line with such an interpretation and find causal evidence of dynastic self-perpetuation among mayors, and show that (1) dynastic mayors have longer careers, and are more likely to win elections and be elected to higher levels of government and (2) higher spending in the year before an election is more likely when dynastic leaders face contested elections and when they are young and inexperienced. Our results are robust to several robustness tests and different estimation strategies (fixed effects, RD and matching estimation on close elections).

The results of this paper enhance our understanding of the role played by families in contemporary democracies, which continue to have a significant role in politics across very different countries. In this light, this study contributes to the debate about inequality and the transmission of wealth and power across generations (Piketty (2013)). We highlight that the dynamics of power transmission across generations have important political consequences, since dynastic politicians behave very differently in terms of both their electoral performance and their policy making. Although there are many potential explanations for the opportunistic behavior of dynastic mayors, the political skills and experience they inherit from their predecessors is likely to shape both their incentives to remain in office and the policies they implement to this end.

Finally, our results point towards the key role of networks in explaining the success of political dynasties. Dynastic leaders behave more strategically when they work in liberal professions, which are typically based on local networks and reputations; when they come from small towns (where again, politics is based mostly on personal ties) and when their family has roots in the local community. 


\section{References}

Alesina, A. and Giuliano, P. (2010). The power of the family. Journal of Economic growth, 15(2):93125.

Alesina, A. F., Troiano, U., and Cassidy, T. (2015). Old and young politicians. National Bureau of Economic Research.

Allesina, S. (2011). Measuring nepotism through shared last names: the case of italian academia. PLoS one, 6(8):e21160.

Amore, M. D. and Bennedsen, M. (2013). The value of local political connections in a lowcorruption environment. Journal of Financial Economics, 110(2):387-402.

Asako, Y., Iida, T., Matsubayashi, T., and Ueda, M. (2015). Dynastic politicians: Theory and evidence from japan. Japanese Journal of Political Science, 16(01):5-32.

Banfield, E. C. (1967). The moral basis of a backward society. Free Press.

Becker, S. O., Boeckh, K., Hainz, C., and Woessmann, L. (2016). The empire is dead, long live the empire! long-run persistence of trust and corruption in the bureaucracy. The Economic Journal, 126(590):40-74.

Bennedsen, M., Nielsen, K. M., Perez-Gonzalez, F., and Wolfenzon, D. (2007). Inside the family firm: The role of families in succession decisions and performance. The Quarterly Journal of Economics, pages 647-691.

Bertrand, M. and Schoar, A. (2006). The role of family in family firms. The Journal of Economic Perspectives, 20(2):73-96.

Besley, T. and Reynal-Querol, M. (2015). The logic of hereditary rule: Theory and evidence. Working Paper.

Blais, A. and Nadeau, R. (1992). The electoral budget cycle. Public Choice, 74(4):389-403.

Bordignon, M., Cerniglia, F., and Revelli, F. (2003). In search of yardstick competition: a spatial analysis of Italian municipality property tax setting. Journal of Urban Economics, 54(2):199-217.

Bordignon, M., Gamalerio, M., and Turati, G. (2013). Decentralization, vertical fiscal imbalance, and political selection. CESifo Working Paper Series.

Bragança, A., Ferraz, C., and Rios, J. (2015). Political dynasties and the quality of government. Working Paper. 
Brender, A. and Drazen, A. (2008). How do budget deficits and economic growth affect reelection prospects? evidence from a large panel of countries. The American Economic Review, 98(5):22032220.

Calonico, S., Cattaneo, M. D., Farrell, M. H., and Titiunik, R. (2016). Regression discontinuity designs using covariates. Working Paper.

Calonico, S., Cattaneo, M. D., and Titiunik, R. (2014). Robust nonparametric confidence intervals for regression-discontinuity designs. Econometrica, 82(6):2295-2326.

Campa, P. and Serafinelli, M. (2015). Politico-economic regimes and attitudes: Female workers under state-socialism. University of Toronto, Department of Economics.

Clark, G. (2014). The son also rises: surnames and the history of social mobility. Princeton University Press.

Clark, G. and Cummins, N. (2015). Intergenerational wealth mobility in england, 1858-2012: Surnames and social mobility. The Economic Journal, 125(582):61-85.

Dal Bó, E., Dal Bó, P., and Snyder, J. (2009). Political dynasties. The Review of Economic Studies, 76(1):115-142.

Daniele, G. and Geys, B. (2015). Organized crime, institutions and political quality: empirical evidence from italian municipalities. Economic Journal, Volume 125, Issue 586, pages F233-F255, August 2015.

Durante, R., Labartino, G., and Perotti, R. (2011). Academic dynasties: decentralization and familism in the italian academia. National Bureau of Economic Research.

Eggers, A. C. and Hainmueller, J. (2009). Mps for sale? returns to office in postwar british politics. American Political Science Review, 103(04):513-533.

Faccio, M. (2006). Politically connected firms. The American economic review, 96(1):369-386.

Feinstein, B. D. (2010). The dynasty advantage: Family ties in congressional elections. Legislative Studies Quarterly, 35(4):571-598.

Fisman, R., Schulz, F., and Vig, V. (2012). Private returns to public office. National Bureau of Economic Research.

Fiva, J. H. and Smith, D. M. (2016). Political dynasties and the incumbency advantage in partycentered environments. CESifo Working Paper Series.

Folke, O., Persson, T., and Rickne, J. (2016). Dynastic political rents. Economic Journal, forthcoming. 
Fukai, S. N. and Fukui, H. (1992). Elite recruitment and political leadership. PS: Political Science E Politics, 25(01):25-36.

Gagliarducci, S. and Manacorda, M. (2014). Politics in the family: Nepotism and the hiring decisions of italian firms. Working Paper.

Gagliarducci, S. and Paserman, M. D. (2016). Gender differences in cooperative environments: Evidence from the us congress. NBER Working Paper No. 22488.

Geys, B. (2016). Political dynasties, electoral institutions and politicians' human capital. Economic Journal, forthcoming.

Godefroy, R. and Henry, E. (2016). Voter turnout and fiscal policy. European Economic Review, 89:389-406.

Hahn, J., Todd, P., and Van der Klaauw, W. (2001). Identification and estimation of treatment effects with a regression-discontinuity design. Econometrica, 69(1):201-209.

Houston, D. J. (2000). Public-service motivation: A multivariate test. Journal of public administration research and theory, 10(4):713-728.

Labonne, J. and Fafchamps, M. (2015). Do politicians' relatives get better jobs? evidence from municipal elections. Evidence from Municipal Elections (May 1, 2015).

Lee, D. S. and Lemieux, T. (2010). Regression discontinuity designs in economics. Journal of economic literature, 48(2):281-355.

McCrary, J. (2008). Manipulation of the running variable in the regression discontinuity design: A density test. Journal of Econometrics, 142(2):698-714.

Michels, R. (1915). Political parties: A sociological study of the oligarchical tendencies of modern democracy. Hearst's International Library Company.

Mosca, G. (1939). The Ruling Class, trans. HD Kahn. New York: McGraw-Hill.

Nannicini, T., Stella, A., Tabellini, G., and Troiano, U. (2013). Social capital and political accountability. American Economic Journal: Economic Policy, 5(2):222-250.

Pareto, V. (1901). The Rise and Fall of Elites: Application of Theoretical Sociology, Piscataway NJ. Transaction Publishers.

Persson, T., Tabellini, G. E., et al. (2003). Do electoral cycles differ across political systems? Innocenzo Gasparini Institute for Economic Research.

Piketty, T. (2013). Le capital au XXIe siècle. Seuil. 
Querubin, P. (2013). Family and politics: Dynastic incumbency advantage in the philippines. Unpublished Manuscript, Massachusetts Institute of Technology.

Querubin, P. and Snyder Jr, J. M. (2011). The control of politicians in normal times and times of crisis: Wealth accumulation by us congressmen, 1850-1880. National Bureau of Economic Research.

Robinson, J. A. and Acemoglu, D. (2008). Persistence of power, elites and institutions. American Economic Review, 98(1).

Rogoff, K. (1990). Equilibrium political budget cycles. American Economic Review, 80.

Rossi, M. (2016). Political dynasties: Evidence from a natural experiment in argentina.". Economic Journal, forthcoming.

Shi, M. and Svensson, J. (2006). Political budget cycles: Do they differ across countries and why? Journal of public economics, 90(8):1367-1389.

Van Coppenolle, B. (2014). Political dynasties and elections. PhD thesis, The London School of Economics and Political Science (LSE). 
Table 16: Variables used in the analysis

\begin{tabular}{|c|c|c|c|}
\hline Variable name & Definition & Time span & Source \\
\hline Dynasty & Whether the politician had a relative in office before first being elected to the council & 1985-2014 & Ministry of Interior \\
\hline First generation & Whether the politician had a relative in office after being elected to the council & 1985-2014 & Ministry of Interior \\
\hline Sex & Sex of the politician & 1985-2014 & Ministry of Interior \\
\hline Age & Age of the politician in years & 1985-2014 & Ministry of Interior \\
\hline Years of education & Minimum number of years to complete the highest degree obtained & 1985-2014 & Ministry of Interior \\
\hline Occupation & Classification of mayors' occupations* & 1985-2014 & Ministry of Interior \\
\hline Experience & Number of years since first elected to the council & 1985-2014 & Ministry of Interior \\
\hline Place of birth & Place of birth in the format Name of the city (Province abbreviation) & 1985-2014 & Ministry of Interior \\
\hline Civic & Whether the politician is from a civic list & 1985-2014 & Ministry of Interior \\
\hline South & Dummy for southern regions & 1985-2014 & Ministry of Interior \\
\hline Population & Population size & 1998-2012 & Ministry of Interior \\
\hline Unemployment & Unemployment rate, in percent & 2001 & Ministry of Interior \\
\hline Surname frequency & Surname frequency at the province level (in thousands of individuals per surname) & 2001 & Ministry of Interior \\
\hline Trust & Level of trust as measured by the "Trust" question in the World Value Survey & $1990 \mathrm{~s}$ & Nannicini et al. (2013) \\
\hline Total expenditures & Total expenditures per capita & 1998-2012 & Ministry of Interior \\
\hline Current expenditures & Current expenditures per capita & 1998-2012 & Ministry of Interior \\
\hline Capital expenditures & Capital expenditures per capita & 1998-2012 & Ministry of Interior \\
\hline Tax revenues & Collected taxes per capita & 1998-2012 & Ministry of Interior \\
\hline Collected taxes & Collected taxes per capita & 1998-2012 & Ministry of Interior \\
\hline Contracted loans & Contracted loans per capita & 1998-2012 & Ministry of Interior \\
\hline Capital transfers & Capital transfers fromthe government or the region, per capita & 1998-2012 & Ministry of Interior \\
\hline Margin (Dynasty) & Margin of the best dynastic candidate & 1993-2014 & Ministry of Interior \\
\hline Margin (Candidate) & Difference in vote shares between the candidate and his best challenger & 1993-2014 & Ministry of Interior \\
\hline Number of candidates & Number of candidates in the election & 1993-2014 & Ministry of Interior \\
\hline Incumbent & Whether the candidate was elected mayor during the previous term & 1993-2014 & Ministry of Interior \\
\hline Term Limit & Whether the mayor is eligible for re-election & 1993-2014 & Ministry of Interior \\
\hline Reelection & Whether the mayor is re-elected & 1993-2014 & Ministry of Interior \\
\hline Term duration & Number of years the mayor remained in office during the term after his election & 1993-2014 & Ministry of Interior \\
\hline Ability of revenue collection & Ratio between actual and expected revenues & 1998-2012 & Ministry of Interior \\
\hline Speed of payment & Share of due expenditures paid during the term & 1998-2012 & Ministry of Interior \\
\hline Growth of private tax base & Yearly growth of private tax base, in percent & 2000-2011 & Ministry of Interior \\
\hline
\end{tabular}

* Calculated by the authors based on the name of the job, using the official socio-professional categories of the Italian government 